\title{
Kapitel 17 \\ Ein umfassendes paulinisches Protonarrativ?
}

\section{Vorbemerkung}

In Kapitel 15, Abschnitt 5 wurde die These aufgestellt, dass Wrights Konzept eines „larger implicit narrative“ grundsätzlich narratologisch sinnvoll erfasst und bearbeitet werden kann, wenn man es als Protoerzählung auffasst, welches in den Paulusbriefen fragmentarisch an die Textoberfläche tritt. Als solcheErzählfragmente des weltanschaulichen Narrativs des Paulus kommen primär in Frage:

- explizite Erzählungen, welche einen Teil der Handlung des umfassenderen mentalen Narrativs versprachlichen,

- isolierte Bezüge auf Ereignisse im Text,

- narrative Substrukturen, welche als strukturierendes Element hinter expliziten Erzählung anderen Inhalts ausgemacht werden können,

- narrative Substrukturen, welche hinter nicht-narrativen Vertextungen auszumachen sind; die narrative Struktur ist dann aus folgenden Elementen zu rekonstruieren:

- aus Bezügen auf Ereignisse, die als tatsächlich geschehen dargestellt werden, die im Text aber nicht mit anderen Ereignissen zu Minimalerzählungen verknüpft sind,

- aus Bezügen auf Ereignisse (oder Ereigniskomplexe mit sinnhafter und temporaler Verknüpfung), welche keine expliziten Erzählungen konstituieren, da sie nicht als in der Vergangenheit geschehen dargestellt werden.

Ein Spezifikum des von Wright ins Auge gefassten Protonarrativs besteht nun darin, dass es möglich sein soll, für Paulus ein einziges umfassendes implizites Narrativ zu rekonstruieren.

Damit geht Wrights Ansatz über die bisher ins Auge gefassten Protoerzählungen hinaus. In der Analyse paulinischer Texte der Kapitel 12-14 lag der Schwerpunkt auf der Frage, inwiefern einzelne Ereignisbezüge überhaupt als Erzählfragmente von Protoerzählungen verstanden werden können. Es wurde dabei jedoch nicht systematisch der Frage nachgegangen, ob all diese Protoerzählungen wiederum zusammen eine narrative Einheit bilden.

Zwar zeigte sich in der Tat mehrfach, dass zunächst isoliert erscheinende Protonarrative, die innerhalb eines größeren Textabschnitts ausgemacht werden konnten, letztlich miteinander verbunden waren (z. B. in Gal 4 und 2. Thess 3). Wrights Anspruch ist jedoch viel umfassender und seine Beurteilung bedarf daher auch einer entsprechend grundsätzlichen Diskussion.

Dazu soll zunächst den Fragen nachgegangen werden, (a) nach welcher Methode bei Wright Ereignisse überhaupt verknüpft werden und (b) was daraus 
für die Synthese größerer Erzählkomplexe - und letztlich eines alles integrierenden Protonarrativs - abzuleiten ist.

Auch wenn im Rahmen dieser Arbeit keine umfassende exegetische Auseinandersetzung mit Wrights Ansatz erfolgen kann, da eine solche sehr viel mehr Raum einnehmen würde, als hier zur Verfügung steht, wird auf diese Weise zumindest der Grundstein für eine solche Evaluation gelegt.

Die hier vorgelegte Analyse legt jedoch nicht nur einen Grundstein für die „eigentliche“ Bewertung. Denn Wrights Ansatz ist nicht nur durch inhaltliche Schwerpunktsetzungen charakterisiert, sondern zeichnet sich auch durch Thesen bezüglich der spezifischen Ausgestaltung und der Signifikanz des paulinischen Protonarrativs aus. $\mathrm{Zu}$ vielen dieser grundsätzlichen Aspekte lässt sich auch bereits im Kontext der hier vorgenommenen narratologischen Betrachtung des Wright'schen Vorgehens definitiv Stellung beziehen.

\section{Verknüpfung aller Ereignisse?}

\subsection{Das Vorgehen nach Petersen}

Wie ist nun eine implizite Erzählung eines Textes im Sinne einer Protoerzählung des Autors zu erheben? Genügt es, sämtliche im Text enthaltenen oder impliziten Ereignis-Repräsentationen zu identifizieren und miteinander zu verknüpfen?

Dies würde zumindest exakt dem Vorgehen entsprechen, das Petersen am Beispiel des Philemon-Briefes in die Exegese eingeführt hatte. ${ }^{1}$ Bei der Rekonstruktion der „stories of letters“ besteht nach ihm die Hauptaufgabe darin, sämtliche im Text explizit benannten Ereignisse zu identifizieren: „All actions referred to are equally actions in the letter's story. “2 Diese seien dann in chronologischer Abfolge zu listen. ${ }^{3}$

Diese referentielle Sequenz müsse nun auch angereichert werden durch all diejenigen Ereignisse, die entweder im Brief selbst impliziert oder von den referentiellen Geschehnissen logisch gefordert würden. ${ }^{4}$ Das bedeutet etwa, dass in Petersens Vorgehen jede auf der Grundlage eines Briefes konstruierte Geschichte das Ereignis der Ankunft des Briefes in der Zukunft beinhalten muss. ${ }^{5}$

1 Petersen, Rediscovering. Neuerdings etwa aufgenommen bei Wendland, „Rhetorical Function.“

2 Petersen, Rediscovering, 45.

3 Petersen, Rediscovering, 47-48.

4 Petersen, Rediscovering, 49: „It will be recalled that the implied actions are referential actions implied in the letter or logically required by the referential sequence."

5 Petersen, Rediscovering, 50. 
Ist mit der auf diese Weise erstellten referentiellen Sequenz nun eine „Erzählung“ im analysierten Brief entdeckt? Liest man Petersens referentielle Sequenz des Philemonbriefs als zusammenhängenden Text, so stellt dieser zweifellos eine Erzählung dar: 6

Philemon incurs a debt to Paul. Paul is imprisoned. Onesimus runs away and incurs a debt to Philemon. Onesimus is converted by an imprisoned Paul. Paul hears of Philemon's love and faith. Paul sends Onesimus back to Philemon. Paul sends a letter of appeal to Philemon and offers to repay Onesimus's debt. Onesimus and the letter arrive. Philemon responds to Paul's appeal. Paul's anticipated visit to Philemon [happens].

Doch um was für eine Erzählung handelt es sich hier? Oder, präziser gefragt, wer erzählt sie? Ist hiermit tatsächlich eine implizit von Paulus erzählte Geschichte rekonstruiert? Die Antwort auf diese Frage ist von großer Bedeutung für eine Evaluation des von Wright in seiner Analyse zugrunde gelegten Vorgehens.

\subsection{Vom Erzählwerk zur Erzählung}

Zunächst ist festzuhalten, dass die Erhebung einer referentiellen Sequenz aus einem Brief, so ungewohnt die Terminologie zunächst auch wirken mag, ein Vorgehen darstellt, das auch in anderen Bereichen der Textanalyse durchaus Analogien findet und dort gut etabliert ist. Auch in der Beschäftigung mit umfangreicheren literarischen Texten findet sich der Leser schließlich regelmäßig in der Situation, nicht einfach eine sinnhaft verknüpfte Aneinanderreihung assertiver Sprachakte über in der Vergangenheit liegende Ereignisse vor sich zu haben. Vielmehr treten die einzelnen Vertextungsmuster in konkreten Texten sehr selten unvermischt auf und dies gilt auch für die Narration in z. B. Romanen. ${ }^{7}$

Wenn eine narratologische Perspektive lediglich auf derartige Texte anwendbar wäre, die ausschließlich Erzählungen konstituierende Elemente beinhalteten, dann wäre sie folglich auch für die allermeisten komplexeren literarischen Erzählungen, Erzählwerke wie Romane etc. (siehe oben, Kapitel 3, Abschnitt 3.4.5),

6 Vgl. Petersen, Rediscovering, 70.

7 Siehe etwa Fludernik, „Genres, Text Type,“ 276 zur Deskription. Dafür spielt sie gerade im Zusammenspiel mit anderen Vertextungsmustern eine wichtige Rolle: „[O]ne can argue that descriptive passages serve a crucial expository function within narrative, in procedural (instructional) and in argumentative texts since they define and introduce the phenomena with which the reader then engages narratively, procedurally, or argumentatively.“ Zur Bedeutung von deskriptiven Abschnitten für Erzählwerke siehe oben, Kapitel 8, Abschnitt 6 die Anmerkungen zu „narrativen Pausen.“ 
bedeutungslos. Denn gerade in diesen begegnen dem Leser schließlich zwar zahlreiche (sprachliche Repräsentationen von) Ereignisse, deren Schilderung aber durch deskriptive Passagen, thematische Exkurse, meta-narrative Kommentare etc. durchbrochen wird. Grundsätzlich ist daher zu sagen: Fragt man im Hinblick auf Paulus nicht nur nach expliziten Erzählungen, die in Reinform vorliegen (evtl. sogar durchgängig nach einem „strikten“ narrativen Muster vertextet sind), sondern analysiert man auch den Zusammenhang anderer sprachlicher Ereignis-Bezüge, so bewegt man sich innerhalb eines narratologisch durchaus recht klar umrissenen Aufgabenbereichs.

Allerdings ist dann auch präzise wahrzunehmen, wie diese Aktivität zu charakterisieren ist. Köppe und Kindt beschreiben die Analyse von komplexeren Erzählwerken wie folgt: ${ }^{8}$

Wir müssen also Ereignisse rekonstruieren und auf ihre (chronologische und sinnhafte) Verknüpfung befragen ... In solchen Fällen kann man auch sagen, dass sich anhand des Romans eine Erzählung rekonstruieren lässt.

Diese rekonstruierte Erzählung entspricht der „Handlung“ des Erzählwerks beziehungsweise dessen „Plot.“9 Dabei darf nicht vergessen werden (vgl. bereits oben, Kapitel 3, Abschnitt 5.3), dass dieser Plot nicht im eigentlichen Sinn ein Bestandteil des Narrativs selbst ist, sondern „vielmehr eine bestimmte (wertende, interpretierende, abstrahierende) Weise, einen Erzähltext zu beschreiben. "10 Es ist dies oft schon allein deshalb der Fall, weil die Präsentation von Geschehnissen gerade in komplexeren Erzählungen nicht immer der Abfolge in der erzählten Welt entspricht. ${ }^{11}$

Dies entspricht der Unterscheidung von Petersen zwischen referentieller und poetischer Sequenz. Auch wenn bei Wright und einigen der Autoren, die mit ihm interagieren, ${ }^{12}$ leicht der Eindruck entstehen kann, es handle sich hier um eine recht innovative narratologische Konzeption, ist damit letztlich nichts anderes gemeint als das, was in der Antike (etwa bei Cicero, Inv., Rhet. Her., Horaz, Ars) bereits durch die Rede von der ordo artificialis im Unterschied zur ordo naturalis

\footnotetext{
8 Köppe und Kindt, Erzähltheorie, 101.

9 „Plot“ meint hier die „Ereignisse ... in der chronologischen Reihenfolge“ (Köppe und Kindt, Erzähltheorie, 102). Siehe bereits oben, Kapitel 3, Abschnitt 5.3, für eine grundsätzliche Einführung dieser Kategorie, die nun in diesem Kapitel im Dialog mit Wright weiter entfaltet werden soll.

10 Köppe und Kindt, Erzähltheorie, 107.

11 Köppe und Kindt, Erzähltheorie, 105.

12 Vgl. etwa White, „Narrative Approach,“ 190-191.
} 
ausgedrückt wurde. In Literary Criticism for New Testament Scholars spricht Petersen entsprechend auch von „story time“ im Gegenüber zu „plotted time.“13

Die Bestimmung eines Plots involviert darüber hinaus aber auch noch eine Entscheidung darüber, welche der präsentierten Ereignisse „zentral“ und welche „marginal“ sind, welche also die Handlung im Sinne des „wesentlichen Ereigniszusammenhangs“ ausmachen. ${ }^{14}$ Differenzierungen $\mathrm{zu}$ dieser Frage können jedoch sehr unterschiedlich ausfallen, je nachdem, welches Verständnis der Geschichte vorausgesetzt wird. ${ }^{15}$ (Siehe dazu auch oben, Kapitel 5, Abschnitt 5.2.2 in Auseinandersetzung mit Barclays Interpretation von Gal 1,13-17.)

Aus methodischer Hinsicht ist daher festzuhalten, dass die „Handlung eines Erzählwerkes das Ergebnis einer Rekonstruktion auf der Grundlage des Textes“ ist. ${ }^{16}$ Eine „Erzählung“ im Sinne eines Textes, der ausschließlich Elemente aufweist, welche den oben genannten Definitionsbedingungen entspricht (also eine Erzählung „in Reinform“ darstellt), entsteht also hier streng genommen erst im Akt der Interpretation. Es ist gegen eine solche Prozedur nun grundsätzlich nichts einzuwenden, sofern der Status des narrativen Konstrukts richtig beurteilt wird.

\subsection{Eine Erzählung auf der Grundlage des „Stoffs“ der Paulusbriefe}

Entsprechend lässt sich dann auch angemessen die Handlung von Ereignisrepräsentationen in nicht-sprachlichen Medien erheben. So schreiben Köppe und Kindt im Hinblick auf Erzählungen, die sich auf der Grundlage eines Filmes bilden lassen: ${ }^{17}$

Diese Rekonstruktionen sind dann semiotische Hervorbringen eigenen Rechts, d.h., es handelt sich um Erzählungen, die das filmisch Gezeigte zum Gegenstand haben bzw. denen das filmisch Gezeigte als Stoff zugrunde liegt.

Aus dem „Stoff“ eines Filmes lassen sich - je nach Perspektive des Wahrnehmenden - sicherlich zahlreiche und recht unterschiedliche explizite Erzählungen formen. ${ }^{18}$ Dasselbe gilt natürlich bezüglich der Ereignisse, die einem komplexen Erzählwerk (etwa einem Roman) entnommen werden. Ebenso könnte man

13 Petersen, Literary Criticism, 49-80. Vgl. Petersen, Rediscoveries, 80, Fußnote 14.

14 Köppe und Kindt, Erzähltheorie, 104.

15 Köppe und Kindt, Erzähltheorie, 107.

16 Köppe und Kindt, Erzähltheorie, 104.

17 Köppe und Kindt, Erzähltheorie, 46. Vgl. zu diesem Thema auch S. 102: „Wir nehmen das Dargestellte als den Stoff einer konzisen Erzählung.“

18 Vgl. Köppe und Kindt, Erzähltheorie, 46. 
selbstverständlich im Anschluss der Erhebung sämtlicher in den Paulusbriefen vorkommenden Ereignisse aus diesem „Stoff“ verschiedene Entwürfe der „Handlung“erstellen.

\subsection{Erzählung des Exegeten oder Protoerzählung des Paulus?}

Dass ein solches Vorgehen an sich unproblematisch ist, bedeutet jedoch nicht, dass dieses Urteil auch für die Ansprüche gilt, die in der Praxis im narrativen Ansatz der Paulusauslegung damit verbunden werden. Würde Petersen lediglich behaupten, dass er aufgrund des Stoffes, den der Philemonbrief liefert, dessen Handlung erhebe, so wäre an dieser Aussage kaum etwas auszusetzen.

Petersen scheint jedoch eine sehr viel engere Beziehung zwischen der auf der Grundlage des Briefes erhobenen Erzählung und dem Briefsender anzunehmen: Zwar betont er, dass wir es lediglich mit einer Liste an Ereignissen zu tun hätten, die aus verschiedenen Perspektiven heraus erzählt werden könnte, ${ }^{19}$ doch hält er daran fest, dass die „,selection and arrangement of actions in our story“ durch die Position des Autors festgelegt seien. ${ }^{20}$ Das gebildete Narrativ ist daher nach Petersen primär die Erzählung des Senders des untersuchten Briefes und nur sekundär die unsere. ${ }^{21}$

So betont er etwa: ${ }^{22}$ „The story we construct from a letter is Paul's fiction, but the one we construct from that story is ours." Dass diese Differenzierung nicht haltbar ist, zeigt sich bereits an Petersens eigener Definition von „fiction“ als „the construction, the making, of an order." ${ }^{23}$ Er liefert aber eben keinen Grund für die Annahme, dass die Konstruktion der Ordnung, welche der Exeget vornimmt, eine Rekonstruktion dessen darstellt, wie Paulus den Zusammenhang ursprünglich konstruierte.

Dieser problematische Anspruch schwingt auch regelmäßig bei gegenwärtigen Autoren mit, ${ }^{24}$ die sich Petersens Methodik bedienen, um implizite Narra-

19 Petersen, Rediscovering, 47.

20 Petersen, Rediscovering, 47.

21 Petersen, Rediscovering, 47 mit Verweis auf BGU I 37, dem Brief eines gewissen Mystarion an einen Priester Stotoetis: „Because our outline of actions is derived from Mystarion, there are actually only two possible narrative voices, Mystarion's and ours, and if ours, we would be telling Mystarion's story. Thus the story is in the first instance his and only derivatively ours."

22 Petersen, Rediscoveries, 14.

23 Petersen, Rediscoveries, 10.

24 Vgl. auch White, „Narrative Approach,“190, der sich durchaus kritisch mit den methodischen Voraussetzungen von Wrights Ansatz auseinandersetzt, in dessen Auseinandersetzung mit Petersens Arbeit aber gerade einen konstruktiven Beitrag sieht. 
tive in Briefen $\mathrm{zu}$ identifizieren. Man vergleiche etwa, wie Wright im folgenden Abschnitt von unserem Akt einer narrativen Konstruktion zu einer Redeweise übergeht, die $\mathrm{zu}$ implizieren scheint, dass Paulus selbst eine solches Narrativ bewusst als Protoerzählung vor Augen hatte: ${ }^{25}$

It would be possible to construct from the Pauline corpus a narrative world of Paul's own life and experience ... That, we may safely say, was the narrative world upon which Paul drew to make sense of his day-to-day experience ... Within all his letters ..., we discover a larger implicit narrative ... Paul presupposes this story even when he does not expound it directly.

Wenn man Wrights implizite Erzählung als Protoerzählung eines Autors versteht, dann ist deren Rückführung auf Petersens Methodik nicht stringent: Für das Vorliegen eines Protonarrativs genügt es nicht, dass die in unserer Liste auftauchenden Ereignisse dem vom Autor produzierten Text entnommen oder zumindest von diesem impliziert sind (d. h. etwa das Ereignis seiner Abfassung etc.). Solange nicht davon ausgegangen werden kann, dass die temporale und sinnhafte Verknüpfung im Mentalen des Autors selbst geschah, wird so immer nur die Geschichte des Exegeten erzählt.

Diese wichtige Unterscheidung kann gut anhand der Diskussion nachvollzogen werden, welche Köppe und Kindt zur Analyse von „Ereignisverknüpfungen“ im Allgemeinen bieten. In der Einführung der Kategorie der ,Erzählung‘ wurde im Anschluss an diese Autoren das Vorliegen einer sinnhaften Verknüpfung (und damit eine Grundbedingung für die Identifizierung einer Erzählung in einem minimalen Sinn) davon abhängig gemacht, ob „der Autor des Textes zu verstehen geben wollte, dass eine solche Verknüpfung vorliegt." ${ }^{26}$ Für den Fall, dass die Absicht des Autors nicht offensichtlich ist, stehen für die Analyse zwei Möglichkeiten zur Verfügung:27

\footnotetext{
Wir können erstens offenlassen, ob der Text als Erzählung gemeint ist. Sein Status ist damit unbestimmt, es handelt sich um einen klassifikatorischen Grenzfall ... Zweitens können wir den Text lesen, als handele es sich um eine Erzählung. Wir sehen in diesem Fall davon ab, dass die Erzählung ein konkretes kommunikatives Artefakt ist, das von den bestimmten Intentionen eines Sprechers abhängig ist, und überlegen uns, welche Annahmen wir sinnvollerweise in den Text hineinlesen können. Strenggenommen benutzen wir damit den Text, um aus ihm eine neue Erzählung zu machen.
}

Es soll nun hier nicht weiter diskutiert werden, ob eine solche kreative Leistung von Paulusforschern nicht auch ihren Eigenwert haben könnte. So wäre es etwa

25 Wright, New Testament, 404-405. Hervorhebungen nicht hinzugefügt.

26 Köppe und Kindt, Erzähltheorie, 55.

27 Köppe und Kindt, Erzähltheorie, 56. Hervorhebung des letzten Satzes nicht im Original. 
möglich, die Frage aufzuwerfen, ob in einer Transformation des Stoffs der Paulusbriefe in Erzählungen nicht auch ein Potenzial für deren Kommunikation in anderen - etwa gegenwärtigen - Kontexten liegen könnte. Letztlich ist eine solche Fragestellung auch vor dem Hintergrund der immer wieder diskutierten „narrativen Theologie“ von großer Bedeutung. ${ }^{28}$

Was für die Fragestellung dieser Arbeit jedoch bedeutsam ist, ist die Erkenntnis, dass bei der Erhebung einer referentiellen Sequenz letztlich der Exeget als Erzähler auftritt. Von einer narratologischen Perspektive auf Paulus kann dann nur bedingt gesprochen werden, da die sorgfältige Analyse und Beschreibung der so erhobenen Narrative letztlich nur das eigene Erzählen untersucht.

Was auf jeden Fall vermieden werden muss, ist die Kombination des „leichten“ Vorgehens Petersens mit einem zumindest implizit erhobenen Anspruch, etwas über das Mentale des Autors - eine Protoerzählung - herausgefunden zu haben. Es ändert sich am hier Gesagten auch dann nichts grundsätzliches, falls wir im Hinblick auf einen bestimmten Ereigniszusammenhang nicht soweit gehen wollen, eine mentale Simulation eines verbalen Erzählaktes zu postulieren, sondern „nur“ von einem weniger weit fortgeschrittenen Grad an Narrativisierung ausgehen: Es handelt sich nur dann um eine wirklich im Text „implizite“ narrative oder an Narrativität grenzende Struktur, wenn die korrespondierende Selektion, temporale Ordnung, sinnhafte Verknüpfung, temporale Umstellung etc. bereits von Paulus vorgenommen wurde.

In dieser Hinsicht zeigt sich erneut (vgl. bereits oben, Kapitel 9, Abschnitt 3.2), wie fatal sich die Tatsache auf die gegenwärtige Paulusforschung auswirkt, dass Fishers „narrative paradigm“ und vor allem dessen Kritik nahezu spurlos an den Vertretern des „narrative approach“ vorübergegangen ist. Denn der hier formulierte Vorbehalt entspricht letztlich exakt den Überlegungen, die Rowland bereits 1989 formuliert hatte. Zunächst erwägt er die Möglichkeit, nicht-narrative Texte im Rahmen des narrativen Paradigmas (d. h. unter Berücksichtigung von „narrative probability“ und „narrative fidelity“) zu untersuchen:29

[E]ven if the form of a work cannot be treated from a narrative perspective, this does not necessarily deny the value of the narrative paradigm. It is possible that a work lacking an explicit narrative structure still can be treated from a narrative perspective, just as a

\footnotetext{
28 Siehe dazu neuerdings Eskola, Narrative Theology. Generell fällt an der neuerlich mit erstarktem Interesse geführten Debatte zu „narrative theology“ im englischsprachigen Raum auf, dass etwa der initiale Beitrag des Linguisten Harald Weinrich, „Narrative Theologie“ nicht beachtet wird. Vgl. aus deutschsprachiger Perspektive Mauz, „Theologie und Narration.“ Zu Weinrichs textlinguistischer Arbeit siehe oben, Kapitel 6, Abschnitt 3.3.4.
}

29 Rowland, „Limiting the Narrative Paradigm,“ 42. 
dramatistic method (the pentad for example) could be applied to works that are not theater. The work could be viewed as containing or drawing upon an implicit story.

Entsprechend wäre grundsätzlich auch eine Analyse von Liberty and Justice for Some anhand solcher Grundsätze möglich:

\begin{abstract}
Liberty and Justice for Some could be interpreted as part of what Fisher calls ,an episode in the story of life“... In this view, the radical right might be treated as mythic villains, representing the power of darkness itself. Censorship and book bans could be seen as representing a return to the dark ages. By contrast, liberals and the People For in particular might be treated as the heroes who are fighting for all the values represented by the American Revolution. A full scale application of the narrative paradigm could flesh out this story by deriving an overall plot outline from the organization of the book. The various chapters then could be treated as incidents building to a climax and the appendices interpreted as an epilogue. Characterization might be developed out of the quotations in each chapter.
\end{abstract}

Den Einwand, den Rowland jedoch im Anschluss formuliert, soll hier in einem längeren Zitat wiedergegeben werden, da sich darin bereits sehr viel findet, was sich eins zu eins auch zur Methodik Petersens und einem entsprechenden Umgang mit den Paulusbriefen sagen ließe: ${ }^{30}$

While such an interpretation could be developed, I suggest that treating Liberty and Justice For Some as an episode in a larger story points more to the potential for critical creativity than it does to the power of the narrative paradigm. To treat Liberty and Justice For Some as a narrative, a critic would have to create his or her own story out of the arguments in the work. Such an interpretation would be virtually impossible to test, since the critic is inventing a story out of what otherwise would be considered discursive material. If one critic did not see the story, another could say simply that he or she did. Textual proof would lose its importance. Moreover, such a process blurs the distinction between works that explicitly tell a story and works for which the critic must discover the story. With enough work, any text could be interpreted as a story, but that critical „work“ may obscure the basic appeal of the text. In this case a narrative interpretation both ignores a far simpler explanation and also has the potential to deny the difference between Liberty and Justice For Some and novels or films that explicitly rely on plot development to make their point.

Es kann als das zweifelhaftes Verdienst Petersens betrachtet werden, dass seine Arbeit die Kluft zwischen der auch hier zur Sprache kommenden kreativen Eigenleistung des Exegeten und der erzählerischen Aktivität des Paulus in der Wahrnehmung vieler Kollegen mit anscheinend spielerischer Leichtigkeit zu überbrücken schien - eine Kluft, für deren sichere Überquerung bei sorgsamer Betrachtung eine sehr viel tragfähigere Konstruktionen nötig ist. Sofern man also nicht nur metaphorisch davon sprechen möchte, die Erzählung „des Paulus“ rekonstruiert

30 Rowland, „Limiting the Narrative Paradigm,“ 43-44. 
zu haben - die Geschichte, die „er erzählt“ - müssen striktere Regeln für die Verknüpfung von Ereignissen zur Anwendung kommen, als dies bei Petersen und Wright der Fall ist.

Ein solcher Rahmen ergibt sich, wenn man die bei Köppe und Kindt so nicht miteinander ins Gespräch gebrachten beiden Kategorien der (1) Handlungsanalyse aufgrund eines Stoffes auf der einen Seite und der (2) mentalen Protoerzählung auf der anderen Seite verbindet. Denn die Kategorie eines mentalen Narrativs im Sinne einer simulierten Erzählung erlaubt es, eine konstruktivere Beziehung zwischen Autorenintention und Ereignisverknüpfung auf Leserseite herzustellen: Zwar lassen sich aus den in einem Text erwähnten Ereignisse in der Regel zahlreiche Protoerzählungen bilden - die wiederum auch explizit erzählerisch verwirklicht werden können - diese Verknüpfung kann jedoch auch explizit mit dem spezifischen Ziel betrieben werden, auf diese Weise Relationen aufzudecken, die auch bereits dem Autor in Form einer Protoerzählung vorschwebten, auch wenn diese Erzählung lediglich fragmentarisch narrativ vertextet wurde.

Es liegt auf der Hand, dass eine solche Rekonstruktion ein anspruchsvolleres Anliegen ist als dasjenige der aufgrund eines Stoffes erfolgenden Konstruktion einer neuen Erzählung, also als der Akt der Ergänzung ${ }^{31}$ sinnhafter Verknüpfungen ohne Bezug zu einer Protoerzählung des Autors. Es stellt sich somit natürlich die Frage, ob der „narrative approach“ auf diese Weise vom Regen in die Traufe gerät: Nachdem Petersen eine leicht identifizierbare Kategorie impliziter Erzählungen bot, deren Aussagekraft sich jedoch als mangelhaft erwies, regt die hier gebotene Diskussion eine Verlagerung des Fokus auf weitaus aussagekräftigere narrative Strukturen an - bezüglich derer man sich dafür aber der kritischen Anfrage stellen muss, ob sie sich dem exegetischen Zugriff nicht weitestgehend entziehen.

Zwar wurde in den Kapitel 9-14 demonstriert, dass bestimmte sprachliche Ausdrucksformen die Annahme von impliziten narrativen Strukturen rechtfertigen, doch waren diese Beispiele stets auf Textabschnitte mit relativ geringem Umfang begrenzt. Die Frage, ob es überhaupt möglich ist, umfangreichere implizite Erzählungen zu rekonstruieren (etwa „the story of the letter“ oder noch mehr), wenn man gleichzeitig die strikte Vorgabe macht, dass die Narrativisierung bereits im Mentalen des Autors zu erfolgen hatte, geht weit über das hinaus, was aus dem in dieser Arbeit bisher gebotenen empirischen Textbefund abgeleitet werden kann.

31 Vgl. Köppe und Kindt, Erzähltheorie, 56: „Wir ergänzen die Ereignisbeschreibungen um sinnhafte Verknüpfungen und erfüllen so die Bedingungen für den minimalen Begriff der Erzählung.“ 


\section{Orientierung an Erzählfiguren?}

\subsection{Die „story of Israel“ im Galaterbrief laut John Barclay}

Auch Exegeten, welche dem Vorgehen Wrights gegenüber kritisch eingestellt sind, postulieren zuweilen umfassendere paulinische Erzählungen. Da sie strengere Maßstäbe an die Rekonstruktion anzulegen scheinen, als dies für das Vorgehen von Petersen gilt, liegt die Frage nahe, ob sich in der bei ihnen zur Anwendung kommenden Methodik eventuell ein Vorgehen ausmachen lässt, welches es rechtfertigen würde, umfangreiche Protonarrative zu synthetisieren (vielleicht sogar ein allumfassendes), also an verschiedenen Stellen im Text identifizierte implizite Erzählungen (vielleicht sogar sämtliche) zu kombinieren.

Solche moderateren narrativen Analysen sind in der Paulusforschung durchaus weit verbreitet, auch wenn sie oft nicht unter dieser Überschrift erscheinen. Es lohnt sich, zur Demonstration dieses Umstands einen Blick auf die oben schon angesprochene Arbeit von Barclay zu „narrativen Dynamiken“ in den Paulusbriefen zu werfen. Einerseits ist Barclay nämlich gegenüber dem Konzept von ,Erzählung, ‘ wie er es bei Wright ausmacht, ausgesprochen kritisch. ${ }^{32}$ Im Kontrast zu einer solch „all-encompassing“ Verwendungsweise des Wörtchens „story“ konzentriert er sich auf explizite Erzählungen: ${ }^{33}$

\footnotetext{
Whatever other „stories“ Paul may, or may not, relate in his letters, my brief here is, in one respect, relatively uncontroversial: Paul manifestly tells some stories about himself in the course of his letters ... In fact, Galatians 1-2 is a quintessential narrative, containing sequential episodes of a single story, complete with time indicators.
}

Auch im Hinblick auf die „story ... of his churches“ und die „story of Israel“ kann Barclay auf zusammenhängende Textblöcke verweisen, nämlich auf Gal 4,12-19 und Röm 9-11. ${ }^{34}$

Auch hier könnte man die Durchgängigkeit der narrativen Vertextung im Einzelnen problematisieren (vgl. etwa die Fragen in Gal 4,15-16) und hinterfragen, ob die von Barclay ins Auge gefassten „stories“ nicht selbst eher Protonarrative sind, auch wenn die narrative Vertextung an der Textoberfläche nur recht wenige Durchbrechungen aufweist. Gemeinsam ist beiden Beispielen jedoch zumindest, dass sie sich auf zusammenhängende Textabschnitte beziehen.

32 Barclay, „Paul’s Story,“ 134, Fußnote 7.

33 Barclay, „Paul’s Story,“ 135.

34 Barclay, „Paul’s Story,“ 135. 
Wenn sich Barclay dann einige Seiten später jedoch der strukturellen Korrespondenz zwischen „Paul's story (as a Jew) and the story of his ,people“ (fellow Jews), as outlined in this letter [Galatians]“ zuwendet, ${ }^{35}$ ist die Situation eine gänzlich andere: Die skizzierte Erzählung „,̈̈ber“ Israel setzt sich zusammen aus Versen, die im Text voneinander getrennt sind und die nun sogar in einer neuen Abfolge präsentiert werden.

Was Barclay hier nacherzählt, hat so bei Paulus nirgendwo eine narrative Entsprechung - eine derartige Erzählung entsteht erst im Erzählakt Barclays, ist also das Produkt seiner Konstruktion. Das resultierende semiotische Artefakt ist in der Sicht des Autors aber offenkundig nicht einfach nur eine aus dem Stoff des Galaterbriefs gebildete Geschichte ohne Bezug zum Apostel, sondern vielmehr eine Nacherzählung einer Protoerzählung, also eine Rekonstruktion auf der Grundlage von Fragmenten dieses mentalen Narrativs zum Thema „Israel“ im Galaterbrief.

Auch Barclay setzt somit voraus, dass wir aufgrund des uns vorliegenden Textes annehmen können, dass Paulus eine Geschichte hätte erzählen können, die in etwa die folgende Gestalt gehabt hätte - auch wenn er sie so nie explizit geäußert hat (bzw. uns diese Äußerung nicht überliefert ist):

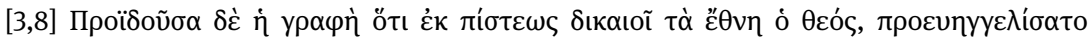

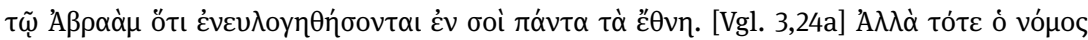

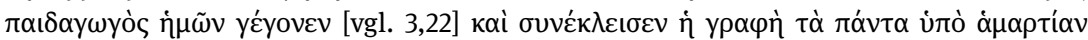

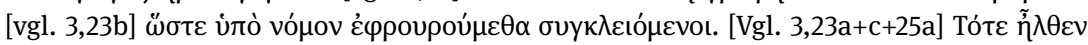

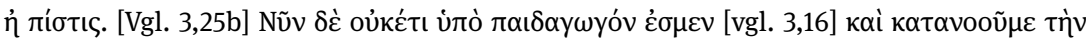

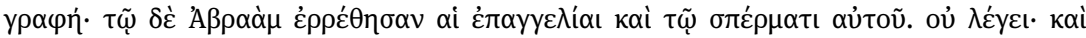

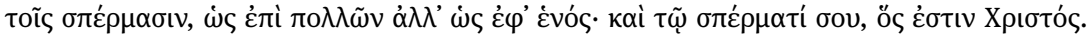

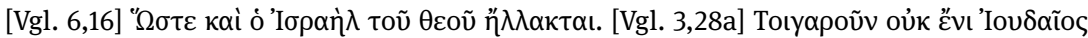

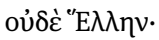

Nicht nur Wright konstruiert also umfassendere mentale Narrative. Es ist ihm daher durchaus zuzustimmen, wenn er in der jüngsten Verteidigung seines Ansatzes betont, dass sich sein grundsätzliches Anliegen nicht groß unterscheide von dem Punkt, den auch „Geertz, Berger and Luckman, Petersen and the thousand writers who have made this and similar points (and with whom the real quarrel should take place if the dissidenters want to pick one)" machten: ${ }^{36}$

I insist that it is possible in principle, and not actually difficult in practice, to discover within the larger worldview and mindset, to which we have remarkably good access, what implicit story Paul is telling, behind, above, underneath, in and through (whatever spatial

35 Barclay, „Paul's Story,“ 144.

36 Wright, Faithfulness, 466. 
metaphor you like) the particular things he says in this or that letter. Discerning this is not arcane, not dependent on some fancy French philosophy, not particularly difficult.

Insofern man, wie hier angeregt, diese implizite Geschichte als Protoerzählung versteht, muss ihm mit dieser Einschätzung wohl recht gegeben werden: Behauptungen, die bezüglich „Erzählungen“ gemacht werden, die aber eigentlich mentale Protoerzählungen zum Gegenstand haben, sind allgegenwärtig. Dies gilt auch in einem großen Maß für die Paulusforschung, in welcher entgegen der eigenen Wahrnehmung auch von Exegeten außerhalb des „narrative approach“ sehr häufig einem Muster gefolgt wird, das dem von Wright in den Grundzügen entspricht.

Das oben angeführte Beispiel von Barclay dokumentiert auch die in der exegetischen Praxis normalerweise zur Anwendung kommende Strategie, mit welcher die Auswahl der Ereignisse vorgenommen wird, welche dann zu einer Erzählung verbunden werden. Anstatt wie Petersen sämtliche Ereignisse zugrunde zu legen, wird eine bestimmte Größe - bei Barclay: „Israel“ - als Fokus festgelegt und dann geprüft, wo im Text auf diese Bezug genommen wird oder zumindest Ereignisse erwähnt werden, die mit Auswirkungen für sie verbunden sind. ${ }^{37}$

\subsection{Erzählfiguren als Kristallisationskerne von Erzählungen}

Mustergültig verdeutlicht dies etwa die klassische Studie von C. K. Barrett, die sich an den Figuren Adam, Abraham, Mose und Christus orientiert. Dabei handelt es sich nach Ansicht des Exegeten aber gerade nicht um eine Untersuchung, die einem von außen an die Paulusbriefe herangetragenen Interpretationsrahmen folgen würde. Vielmehr ist die Grundstruktur durch folgende Annahme über das Geschichtsverständnis des Paulus vorgegeben: „Paul sees history gathering at nodal points, and crystallizing upon outstanding figures.“"38

Auch in der neueren, mit dem „narrative approach“ verbundenen Herangehensweise wird die Analyse im Regelfall mit Fokus auf verschiedene Entitäten durchgeführt, sodass es im Resultat (siehe Abb. 59) zu mehreren, thematisch differenzierten Erzählungen kommt.

37 Vgl. in dieser Hinsicht ganz im Sinne von Hays die Suche nach „Christuserzählungen“ in Dragutinović, Nicklas, Rodenbiker und Tatalović, Hg., Christ.

38 Barrett, Adam, 5. Hervorhebung nicht im Original. 


\begin{tabular}{|c|c|}
\hline Witherington ${ }^{39}$ & $\begin{array}{l}\text { 1. World } \\
\text { 2. Israel } \\
\text { 3. Christ } \\
\text { 4. Christians } 40\end{array}$ \\
\hline Dunn ${ }^{41}$ & $\begin{array}{l}\text { 1. God and creation } \\
\text { 2. Israel } \\
\text { 3. Jesus } \\
\text { 4. Paul }\end{array}$ \\
\hline Wright $^{42}$ & $\begin{array}{l}\text { 1. God and Creation } \\
\text { 2. Humans } \\
\text { 3. Israel } \\
\text { 4. Jesus } \\
\text { (5. the church) }\end{array}$ \\
\hline
\end{tabular}

Abb. 59: Erzählfiguren als Differenzierungskriterium zwischen verschiedenen Erzählungen.

Gegenüber der Analyse von Barclay - der sich auf den Galaterbrief konzentriert, also das Produkt eines zusammenhängenden Äußerungsaktes - wird im narrativen Ansatz allerdings (a) in der Regel keine Einschränkung auf ein bestimmtes Schreiben vorgenommen.

Eine weitere Differenz besteht bezüglich der Frage (b), wie diese einzelnen Erzählungen/Erzählstränge miteinander in Beziehung stehen: Während Barclay in den einzelnen Erzählungen einen gemeinsamen Bezug auf das Christusereignis sieht, sodass die Geschichte über Paulus, den „paradigm Jew,“ zum „microcosm of the story of his people“ werde, ${ }^{43}$ und annimmt, dass eine „striking, though subtle, homology“ zwischen der Geschichte des Paulus und der seiner Gemeinde bestehe, ${ }^{44}$ geht etwa Wright davon aus, dass die einzelnen Erzählungen

39 Witherington, Narrative Thought World, 5.

40 Longenecker, „Narrative Interest,“ 12 ist beim Zitieren von Witherington, Narrative Thought World, 5 ein schwerwiegender Fehler (ein Homoioteleuton) unterlaufen, der zum Resultat hat, dass er ihm unterstellt, dass er die Erzählung über die Christen (anstatt der über Christus!) für das zentrale Element hält:

„... the story of Christians, including Paul himself, which arises out of all three of these previous stories and is [...] the hinge, crucial turning point, and climax of the entire larger drama, which more than anything else affects how the Story will ultimately turn out.“

„... the story of Christians, including Paul himself, which arises out of all three of these previous stories and is the first full installment of the story of a world set right again. Christ's story is the hinge, crucial turning point, and climax of the entire larger drama, which more than anything else affects how the Story will ultimately turn out.“

41 Dunn, Theology, 18.

42 Wright, Faithfulness, 475-537.

43 Barclay, „Paul's Story,“ 144.

44 Barclay, „Paul’s Story,“ 145. 
zu einer einzigen Erzählung verbunden werden können (siehe den nächsten Abschnitt 5 zum konkreten Gepräge dieses umfassenden Protonarrativs).

Trotz dieser Unterschiede gilt: Das grundsätzliche Vorgehen - (1) die Orientierung an einer Erzählfigur und (2) die Kombination von Ereignissen, die nicht direkt im Text und nicht in dieser Abfolge direkt zur Sprache kommen - ist dennoch dasselbe. Das Potenzial und die Gefahren einer solchen Rekonstruktion eines Plots auf der Grundlage vorausgesetzter „Erzählfiguren“ gilt es im Folgenden auszuloten. ${ }^{45}$ Die in diesem Kontext geäußerte Kritik trifft dann nicht nur den spezifischen Entwurf Wrights (siehe Abschnitt 5.4), sondern zumindest teilweise auch die außerhalb des narrativen Ansatzes anzutreffende Rede über Erzählungen bei Paulus.

\subsubsection{Eine Erzählung oder mehrere?}

Ein erstes Problem besteht darin, dass die zu einer Erzählung zusammengefügten Ereignisse eigentlich mehreren separaten Erzählakten zum selben Thema entsprechen. Gerade wenn verschiedene Schriften herangezogen werden, ist natürlich mit der Möglichkeit zu rechnen, dass sich in der Zwischenzeit das Wissen über die erzählten Ereignisse oder deren Bewertung geändert hat. Die Protoerzählung über Israel im Galaterbrief muss daher nicht notwendigerweise denselben Aufbau haben wie diejenige, die auf der Grundlage des Römerbriefs rekonstruiert wird. Doch selbst wenn keine größeren Entwicklungen in der Meinung des Erzählers angenommen werden, gilt doch, dass es sich um verschiedene Erzählungen handelt, die in ihrer Eigenständigkeit wahrzunehmen sind, da je nach kommunikativem Kontext die narrative Vertextung mit ganz unterschiedlicher Kommunikationsintention erfolgen kann.

Dies gilt auch innerhalb derselben Schrift, wo Erzählungen über dieselben Ereignisse der realen Welt in unterschiedlicher Weise in den Diskurs eingebunden sein können. Die Zusammenschau, die Hays im Hinblick auf Gal 3,13-14 und

45 Zum hier angenommenen recht breiten Konzept der ,Figur‘ vgl. Köppe und Kindt, Erzähltheorie, 119, welche das Vorhandensein der Beschreibung einer Figur in einem (fiktionalen) Text davon abhängig machen, ob er „zu der Vorstellung einlädt, dass das Beschriebene ein Mensch / eine Person (oder ein quasi-menschlicher Gegenstand) ist.“ Die Klassifizierung der hier gelisteten Elemente ist im Einzelnen natürlich unterschiedlich deutlich: „Jesus“ als Figur zu bezeichnen, ist unproblematisch. „Israel“ kann als Kollektiv als Figur auftreten oder steht als Chiffre für Einzelpersonen wie Abraham. Die „Welt“ scheint auf den ersten Blick eher ein Schauplatz zu sein, tritt jedoch auch personifiziert auf oder steht eigentlich für eine Geschichte über Gott als Schöpfer. 
Gal 4,3-6 vornimmt, ist somit nicht unproblematisch. ${ }^{46}$ Der Vergleich von Gal 4,3-6 und 8-12 zeigt sogar, wie Paulus von dieser Möglichkeit eines unterschiedlichen erzählerischen Zugriffs auf denselben Ereigniszusammenhang ganz bewusst Gebrauch macht (Kapitel 9, Abschnitt 5; vgl. Kapitel 16, Abschnitt 3). Es ist zwar richtig, dass Paulus hier die Leser dazu bringen möchte, die Ereignisse insgesamt miteinander in Beziehung zu setzen - den erwünschten kommunikativen Effekt erzielt er jedoch gerade durch die Spannung, die im Versuch einer solchen Gesamtsynthese entsteht.

\subsubsection{Erzählfigur und Rolle in der Erzählung}

Das Problem liegt in sogar noch größerem Maße vor, wenn die als Ausgangspunkt der Rekonstruktion gewählte Figur in den besagten eigenständigen Erzählungen nicht dieselbe Rolle spielt. Es ist der Fall denkbar, dass das eine Protonarrativ tatsächlich um diese Entität kreist, dass ihr im anderen Protonarrativ jedoch nur eine Nebenrolle zukommt - oder es sogar in beiden impliziten oder expliziten Erzählungen eigentlich um etwas anderes geht.

Je nachdem, was für ein Plot und Thema vorliegt, kann die Rolle ein und derselben Figur sehr unterschiedlich bewertet und dargestellt werden. Auffällig an Barclays Rekonstruktion ist etwa, dass in den einzelnen Israel-Fragmenten ganz unterschiedliche Perspektiven eingenommen werden. Selbst wenn man annimmt, dass in allen Aussagen wirklich dasselbe „Israel“ gemeint ist (also etwa trotz der Rede von „uns“ und der Charakterisierung von „Israel“ als das „Israel Gottes“), müsste zunächst ausgeschlossen werden, dass diese unterschiedliche Benennung nicht mit einer unterschiedlichen Fokalisierung zu tun hat, also etwa einmal eine Erzählung aus Sicht des Apostels erfolgt, ein anderes Mal aus Sicht der Heiden etc. ${ }^{47}$

46 Hays, Faith, Kapitel 3. Vgl. dazu oben, Kapitel 3, Abschnitt 4.3.

47 Eine Alltagssituation mag das verdeutlichen: Es ist anzunehmen, dass bestimmte gemeinsame Bekanntschaften eines Paares sowohl in Erzählungen über den eigenen Lebensweg als auch in solchen über den des Partners/der Partnerin eine Rolle spielen. Tritt bei einem sozialen Ereignis eine Person zu dem Kreis, in welchem ein Ehemann gerade eine Anekdote zum besten gibt, besteht die Möglichkeit, dass der Hinzukommende dieses Erzählfragment der falschen vorausgesetzten Protoerzählung zuweist - mit potenziell verheerenden Konsequenzen: Denn wer in der Erzählung über die Ehefrau eher als Bösewicht auftritt, kann in der eigenen Biographie dennoch einen heldenhaften Auftritt hinlegen. Auch bei gleichbleibender Perspektive ist natürlich eine differenzierte Rollenzuschreibung möglich, bei welcher eine Person mal positiv, mal negativ auftreten kann. 


\subsubsection{Unterschiedliche Erzählstränge einer Erzählung}

Aus der Sicht des narrativen Ansatzes könnte man entgegnen, dass sich dieses Problem nur stellt, wenn man wie Barclay Zurückhaltung walten lässt, was die Kombinierbarkeit der individuellen Erzählungen angeht. Wenn die einzelnen identifizierten Protoerzählungen selbst Teil eines umfassenderen Protonarrativs sind, dann, so könnte man argumentieren, sollte einer solchen Synthese nichts im Wege stehen: Wenn sämtliche bei Paulus zur Sprache kommenden Ereignisse zum selben Narrativ gehören, kann man - so der intuitive Eindruck - gar nicht in die Gefahr kommen, etwas zu kombinieren, was nicht zusammengehört. Dabei wird jedoch übersehen, dass das hier geäußerte Bedenken nicht nur für eigenständige Erzählungen, sondern auch für zu differenzierende Erzählstränge derselben Erzählung gilt und dort zum Teil sogar noch verschärft vorzubringen ist.

Ein grundsätzliches Problem besteht nämlich bereits in dem Umstand, dass sich ein Plot überhaupt gar nicht notwendigerweise aufgrund einer Figuren-Kontinuität konstituieren muss. Schon Lämmert schreibt etwa, verschiedene Handlungsstränge würden an „mindestens einem der folgenden drei Kriterien [divergieren]: Verschiedene Handlungszeit - verschiedener Schauplatz - verschiedene Person. "48 Auch der geteilte Bezug auf ein zentrales weiteres Ereignis kann eine solche Funktion übernehmen. 49

Daraus folgt einerseits natürlich, dass Handlungen von Protoerzählungen, die sich, beispielsweise, über einen geteilten Handlungsort bestimmen ließen, für ein an Erzählfiguren orientiertes Raster völlig unsichtbar wären und zwangsläufig übersehen würden.

Zweitens besteht auch hier die Gefahr, Aussagen über eine Figur fälschlich zu kombinieren, sie also nun - nicht verschiedenen Erzählungen aber - verschiedenen Erzählsträngen derselben Erzählung zu entnehmen, in denen die Figur aber jeweils eine ganz unterschiedliche Rolle spielen kann. Dadurch würde entweder ein Plot mit Ereignissen angereichert, die nicht zu diesem Handlungsstrang gehören, oder - im schlimmsten Fall - sogar eine Handlung aus Ereignissen zusammen „gebastelt,“ welche zwar allesamt einer (Proto-)Erzählung entnommen sind und auch alle mit derselben Figur zu tun haben, welcher aber Paulus überhaupt nie einen zusammenhängenden Handlungsstrang gewidmet hatte. ${ }^{50}$

48 Lämmert, Bauformen, 44.

49 Köppe und Kindt, Erzähltheorie, 109.

50 Im eben angeführten Beispiel des Smalltalks hieße das: Ein noch schlimmeres Missverständnis läge dann vor, wenn die neu hinzutretende Person annähme, der Mann erzähle gerade eine Geschichte über den besagten Bekannten, dass dieser also die Figur wäre, welcher der anzunehmende Plot zu folgen habe. 
Ein solcher Negativbeweis, dass Paulus etwa nie ein Narrativ mit einem dem „treuen Messias“ gewidmeten Plot gebildet ${ }^{51}$ habe, wird freilich kaum möglich sein. Andersherum darf das Fehlen der Evidenz gegen ein solches Protonarrativ auch nicht einfach als Evidenz für dessen Annahme herangezogen werden.52 Selbst wenn die Handlungsstränge, welche die Gesamthandlung eines umfassenderen Protonarrativs bilden, richtig erkannt wären, müssten in der Synthese noch weitere Schwierigkeiten überwunden werden - etwa einzelne Ereignisse und stützende Figuren richtig eingeordnet werden. Auch wenn ein Element tatsächlich nur in einem Handlungsstrang der Erzählung vorkommt, besteht natürlich die Gefahr, es dem falschen Handlungsstrang zuzuordnen.

Auch wenn Wright es nicht in genau diesen Worten ausdrückt, ist dies exakt derjenige Fehler, den er vielen seiner Kollegen an einem bestimmten Punkt attestiert: Geht man davon aus, dass die Aussagen des Paulus über die Torah im Rahmen einer Protoerzählung über individuelle Erlösung oder auch die Heilsgeschichte der Menschheit im Allgemeinen zu verstehen sind und nicht innerhalb der Erzählung über Israel, rekonstruiert man laut Wright ${ }^{53}$ ein Protonarrativ, das Paulus so nie vertreten hat (noch hätte) und das unweigerlich im Konflikt mit anderen seiner Erzählzüge steht. ${ }^{54}$

51 Wenn man zeigen könnte, dass Paulus einem bestimmten zentralen Thema, das der Exeget an ihn heranträgt, keinen eigenen Handlungsstrang gewidmet hätte, hieße das nicht, dass dieses ihn nicht „interessiert“ hätte (auch wenn das eine Möglichkeit darstellt). Logisch implizieren würde die Beobachtung aber eben, dass er sich diesem Thema eben nicht in Form eines mentalen Narrativs gewidmet hat - ebenso wie ja auch im Hinblick auf explizites Erzählen gilt, dass es Themen gibt, die Paulus auf narrative Weise aufgegriffen hat, und andere, die er durch nicht-narrative Vertextungen entfaltet hat.

52 Das hier Gesagte gilt übrigens natürlich auch umgekehrt für die fälschliche Orientierung an einem vorausgesetzten Handlungsort. Um dies wieder am Beispiel der Alltagserzählungen zu verdeutlichen: Handelt es sich bei der erzählenden Person um einen Historiker, wird man wohl auch nicht fehl gehen, zu vermuten, er könne prinzipiell eine Erzählung über die Geschichte seines Wohnortes bieten. Zugleich ist jedoch zu vermuten, dass die Stadt auch als Schauplatz zahlreicher Erzählungen dort gemachter Erfahrungen (Studium, Familiengründung, Arbeit, Freizeitgestaltung usw.) dient. Wer nun verspätet zu einem Gespräch hinzutritt und ein chronistisches Erzählinteresse unterstellt, wird zwangsläufig fehlgeleitet werden, wenn er unter anderem Gesichtspunkt erzählte Episoden als vom Erzähler für die Geschichte der Stadt zentral angesehen einstuft. Handlungsstränge, die einzelne Personen oder Ereignisse betreffen, können also auch durch einen nicht angebrachten Fokus auf einen Handlungsort aufgelöst und falsch verbunden werden.

53 Vgl. Wright, Faithfulness, 505.

54 Auch hier kann die Alltagssituation das Gemeinte illustrieren: Erzählt ein Ehemann bei einer sozialen Zusammenkunft über den letzten Urlaub, so kann dieser durchaus zwei Handlungsstränge aufweisen, die sich nur selten berühren, wenn er und seine Partnerin die meiste Zeit jeweils für sich verbrachten. Es ist also durchaus möglich, dass ein bestimmtes Ereignis 
Entsprechend ließe sich auch wieder gegenüber der Rekonstruktion von Barclay etwa die kritische Anfrage stellen, dass die von ihm zusammengestellten Aussagen sehr unterschiedlich auf die Größe „Israel“ Bezug nehmen. Man könnte daher sogar die grundsätzliche Frage aufwerfen, ob diesen Fragmenten im Text überhaupt ein Israel gewidmeter Erzählstrang gegenübersteht. Zwar ist natürlich damit zu rechnen, dass Paulus auch über das Schicksal „seines Volkes“ nachdachte, aber es ist zumindest auffällig, wie heterogen die Subjekte in der vorausgesetzten Protoerzählung sind: Schrift, Gott, Heiden, Gesetz, Wir, Glaube, die Verheißungen, der Nachkomme, Israel (Gottes), Jude, Grieche. Zumindest theoretisch spricht daher nichts dagegen, die Frage aufzuwerfen, ob hier nicht eher ein Narrativ über z. B. „die Verheißung“ im Hintergrund steht.

\subsubsection{Unvollständige Handlungs-Rekonstruktionen}

Der fälschlichen Integration eines Ereignisses in einen Erzählstrang entspricht auf der Gegenseite das Problem, dass starke Figuren-Fokussierung auch mit einem Übersehen zentraler Handlungselemente einhergehen kann. Selbst wenn man die in einem Text zur Sprache kommenden Ereignisse korrekt einem zusammengehörigen Erzählstrang im Mentalen des Autors zugeordnet hätte, könnte noch immer nicht automatisch von einer gelungenen Anwendung des Figuren-Kriteriums gesprochen werden. Dies liegt daran, dass letztlich kaum zu entscheiden ist, ob die rekonstruierte Handlung im Vergleich zur Handlung der simulierten Erzählung nicht deutlich verarmt wäre.

Es ist eben durchaus von Bedeutung, dass der Zusammenhang eines an einer Figur orientierten Handlungsstrangs sich daraus ergibt, dass die Ereignisse „in der einen oder anderen Weise“ mit dieser Figur verbunden sind. ${ }^{55}$ Und dies schließt selbstverständlich auch viele Situations-Typen ein, in deren sprachlichen Repräsentationen die besagte Figur weder als Agens noch als Patiens auftritt, die aber dennoch eine wichtige stützende Funktion haben.

tatsächlich nur in einem einzigen Plot auftritt (weil die Ehefrau im Urlaub den Sonnenbrand bekam, aber das Entspannungserlebnis ihres Partners dadurch unbeeinflusst blieb). Wieder liegt ein großes Missverständnis vor, wenn ein verspätet hinzutretender Zuhörer dieses Ereignis in den anderen Plot integriert, der aufgrund der Situation (,Er erzählt vermutlich, wie sein Urlaub war ... ') und aufgrund der sachlichen Nähe (,Er erzählt davon, dass die Sonnencreme aufgebraucht war und er ist auch etwas rot um die Nase.`) fälschlicherweise angenommen wird.

55 Köppe und Kindt, Erzähltheorie, 108. 
Man vergleiche etwa die folgenden drei Fragmente eines an der Minimalerzählung von Köppe und Kindt angelehnten Narrativs, bei denen die Erzählfigur des Apfels in einer zentralen Ereignisschilderung gar keine Rolle spielt:

(1) „Der Apfel hing am Baum ... “

(2) „Ein starker Wind kam über das Land ... “

(3) „Der Apfel fiel vom Baum ... “

So gesehen könnte man die aufgrund des heterogenen Subjekts erwogene Anfrage an Barclays Israel-Erzählung auch umkehren: Man könnte ihr vorwerfen, dass sie ausschließlich solche Elemente aufweist, die immer noch sehr eindeutig mit Israel in Verbindung stehen (z. B. das Gesetz), dass aber ja nicht gesagt sei, dass Paulus' Erzählung nicht auch ganz andere Elemente enthielte. Was bestimmt hier die Entscheidung darüber, was noch zur Israels-Geschichte gehört und was damit nicht in Verbindung steht? (Etwa auch die Annahme einer allgemeinen jüdischen Erzählung, aus deren konkretem Vorliegen bei anderen Autoren dann die relevanten Elemente für Paulus abgeleitet werden können?)

Der von Wright unternommene Versuch, verschiedene Handlungsstränge zu kombinieren und die Gesamt-Erzählung auf diese Weise mit Figuren und Ereignissen anzureichern, stellt vor diesem Hintergrund betrachtet also nicht nur eine methodische Verkomplizierung dar. Er trägt vielmehr auf durchaus angemessene Weise dem Umstand Rechnung, dass Erzählungen in den seltensten Fällen nur Aussagen zu einer einzigen Größe enthalten.

Obwohl also auf den ersten Blick der Entwurf von Barclay weitaus bescheidener wirkt, da er sich nur auf Aussagen beruft, die (mehr oder weniger klar erkennbar) dieselbe Erzählfigur betreffen, bedeutet dies nicht, dass er deswegen plausibler sein müsste. Eine zu geradlinige, kaum Nebenhandlungen aufweisende Erzählung ist, im Gegenteil, gerade nicht üblich - schon gar nicht, wenn sie einen gewissen Gehalt aufweisen soll (vgl. zu den Bedingungen gehaltvollerer Erzählungen Kapitel 3, Abschnitt 3.4.4).

\subsubsection{Fazit}

Zusammenfassend ist also zu sagen: Ist man im Hinblick auf implizite Erzählungen am tatsächlichen (mental simulierten) Erzählakt interessiert, dann kann man als Maßstab für die Kombination verschiedener Ereignisse nicht allein die Tatsache heranziehen, dass sie sich auf dieselbe Figur beziehen. Wie auch im Fall von expliziten Erzählungen muss die Eigenständigkeit verschiedener Erzählakte respektiert werden. In keinem von beiden Fällen ist es ohne weiteres möglich, selbstständige Erzählungen miteinander zu verbinden, um umfassendere Handlungen zu bilden. 
Natürlich ist es möglich, dass der bzw. ein Plot einer Erzählung einer bestimmten Erzählfigur folgt. Eine Rekonstruktion einer Erzählung aufgrund einer ins Zentrum gerückten Figur setzt jedoch bereits ein Vorverständnis dieses Plots voraus. In den meisten Fällen (d. h., wenn nicht etwa durch die Überleitung bekannt ist, was für eine Erzählung folgt; vgl. Kapitel 8, Abschnitt 5) gehört die Frage nach der einen Plot konstituierenden Erzählfigur daher in die Phase der interpretativen Auswertung des zuvor zu erhebenden Narrativs. ${ }^{56}$ Wo in der exegetischen Praxis aber ein einer Erzählfigur folgender Handlungsstrang identifiziert wird, indem auf ein rekonstruiertes Narrativ zurückgegriffen wird, welches wiederum unter der Voraussetzung einer solchen Orientierung gebildet wurde, liegt ein klassischer Zirkelschluss vor.

\subsection{Kontinuität innerhalb der erzählten Welt als Rettungsversuch der Annahme umfassender Protonarrative}

\subsubsection{Erzählung ohne simuliertes Erzählen?}

Es ist durchaus nicht ausgeschlossen, dass aus verschiedenen Erzählungen und Ereignisbezügen ein umfassenderes Protonarrativ gebildet werden kann, dessen Handlung sich in der Interpretation dann als an einer Erzählfigur orientierend herausstellt. Die dabei zu beachtenden Leitlinien werden unten (Abschnitt 4) noch expliziert werden. Schon hier sollte jedoch klar geworden sein, dass eine solche Synthese ein durchaus komplexes Geschehen darstellt, welches mit vielen Schwierigkeiten für die exegetische Praxis verbunden ist.

Man könnte daher versucht sein, doch noch nach einem gehaltvollen Verständnis einer „Erzählung des Paulus“ zu suchen, welches aber ohne das Konzept des simulierten Erzählens und die damit verbundenen strikte Annahmen über die Autorenintention auskommt. Daher soll hier noch kurz auf denkbare Versuche eingegangen werden, die weitreichenden Postulate des narrativen Ansatzes über umfassende Erzählungen in den Paulusbriefen dadurch zu retten, dass auf die Kontinuität auf der Ebene des Erzählten verwiesen wird, um die Rede von Paulus „als Erzähler“ zu rechtfertigen.

Als Beispiel kann hier wieder eine angebliche paulinische Erzählung „über Israel“ herangezogen werden. Sieht man für den Moment von der unsicheren

56 Entsprechend würde Barclay auf die hier erwogenen - grundsätzlich möglichen - Einwände natürlich auch erwidern können, dass seiner Rede von einer Israels-Geschichte natürlich eine entsprechende Analyse des Textes und Rekonstruktion einer Erzählung vorausgegangen sei, deren Plot er dann als auf Israel bezogen interpretiert hätte, um diesen dann an dieser Stelle paraphrasierend wiederzugeben. 
Referenz von Stellen wie Gal 6,16 ab, könnte man argumentieren, dass Paulus bei den in verschiedenen Kontexten vorliegenden Erwähnungen von 'I $\sigma \rho \alpha \eta ́ \lambda$ ja immer dieselbe Größe vor Augen gehabt habe. Eventuell ließe sich die Menge der relevanten Aussagen auch noch dadurch signifikant erweitern, dass man auch noch Ausdrücke wie ouyyćvnৎ etc. mit berücksichtigen würde. All diese Aussagen beziehen sich auf dieselbe, sich freilich in der realen Welt diachron verändernde Entität. Aus diesen Annahmen könnte man dann die folgende These ableiten: Zumindest „indirekt“ liefert Paulus auf diesem Wege also doch eine Erzählung über Israel - und eine Autobiographie etc.

\subsubsection{Erzählte Welten}

Eine solche Argumentation weist auf den ersten Blick durchaus eine gewisse Triftigkeit auf, wie sich gut im Vergleich mit fiktionalen Erzählungen darstellen lässt: Dass Lucy durch den Schrank hindurchgeht und Harry Potter durch die Absperrung zwischen Gleis 9 und Gleis 10, ereignet sich in unterschiedlichen „fiktiven Welten.“ Mit dieser Redeweise soll der Tatsache Rechnung getragen werden, dass Erzählungen immer eine Imaginationstätigkeit anregen, die über die geschilderten Ereignisse hinausgehen. ${ }^{57}$ Die Grenzen dieser Welten können nicht einfach überschritten werden. Wer Lucy und Harry Potter nun in derselben Erzählung auftreten lässt, vollbringt damit einen eigenständigen Erzählakt. Demgegenüber ist es aber möglich, innerhalb der Welten im Rahmen der dort geltenden Gesetzmäßigkeiten Schlussfolgerungen über Relationen zwischen Figuren und Ereignissen anzustellen, die im Text selbst nicht expliziert sind.$^{58}$ Nun laden auch faktuale Erzählungen zu einer umfassenden Vorstellungstätigkeit ein, die über die dargestellten Ereignisse hinausgeht. ${ }^{59}$

Insofern die in separaten (simulierten) Erzählakten hervorgebrachten Protoerzählungen des Paulus faktualer Natur sind, rekurrieren sie gemeinsam auf dieselbe Wirklichkeit als „erzählte Welt“ (also anders als im Fall der Erzählwerke Narnia und Harry Potter). Man könnte folglich argumentieren, dass die Synthese verschiedener faktualer Protoerzählungen zu einem einzigen zusammenhängenden Handlungsstrang doch mehr über den Apostel als Erzähler verrät, als hier bisher zugestanden wurde. Ja, letztlich wäre auch die Synthese ganz verschie-

57 Vgl. zu diesem Konzept Köppe und Kindt, Erzähltheorie, 82.

58 Die Prinzipien, anhand derer entschieden wird, was in einer fiktiven Welt der Fall ist, sind sehr umstritten. Vgl. Köppe und Kindt, Erzähltheorie, 144.

59 Vgl. Köppe und Kindt, Erzähltheorie, 205. Siehe grundsätzlich oben, Kapitel 3, Abschnitt 5.4 zu Fiktionalität und Faktualität. 
dener Handlungsstränge - etwa das Volk Israel auf der einen und den Apostel Paulus selbst auf der anderen Seite betreffend - vor diesem Hintergrund problemlos möglich, insofern ja immer dieselbe Wirklichkeit den Kontext des Erzählten liefert.

Ein solches Vorgehen scheint zumindest auf den ersten Blick der Praxis einer neutralen Edition eines Erzählwerks eines verstorbenen Schriftstellers zu gleichen, dessen Werk nur in separaten Kapiteln vorliegt, von denen man aber weiß, dass diese zusammen eine zusammengehörige Handlung zum Ausdruck bringen sollen. Letztlich liegt wohl auch eine solche Vorstellung zugrunde, wenn Petersen von der „narrative world“ eines Briefes spricht und diese eingebettet sieht in „Paul's narrative world,“ also die narrative Welt, die sich aus der Gesamtheit der Briefe ergibt. ${ }^{60}$

\subsubsection{Auswahl und Darstellung der Ereignisse der erzählten Welt}

Bei genauerer Betrachtung zeigt sich jedoch, dass dies keine Lösung darstellt. Erstens müsste eine solche Erzählung dann konsequenterweise auch wirklich aus allen Ereignissen bestehen, die man im Hinblick auf Paulus erheben könnte. Denn insofern sie alle auf dieselbe Welt bezogen sind, gibt es nun auch keinen Grund einzelne Ereignisse oder Gruppen davon einfach auszuschließen.

Daran haben jedoch die Vertreter einer einheitlichen impliziten Erzählung bei Paulus dezidiert kein Interesse. So schreibt Witherington: ${ }^{61}$

This Story is a tale as large as the universe and yet as small as an individual human being. It is, however, not a Story about everything, not even about all of human history.

Eine „story about everything“ scheint allerdings kaum vermeidbar, wenn man Petersons Ansatz konsequent zu Ende denkt. Demgegenüber fällt auf, dass seine eigene Auswahl der ,implied actions[, which] are referential actions implied in the letter or logically required by the referential sequence,"62 sehr sparsam ausfällt. Es ist überhaupt nicht einzusehen, weshalb die Ankunft von Brief und Sklave bei Philemon ,the only apparently implied actions necessarys for our referential sequence" sein sollten. ${ }^{63}$

Irgendwo zwischen Flucht des Onesimus (Ereignis 3) und seiner Rücksendung (Ereignis 6) wird man doch wohl etwa auch ausreichend Schlaf und

60 Petersen, Rediscovering, 14. Dieser Aspekt wird von Wright betont aufgegriffen: Wright, New Testament, 404-405.

61 Witherington, Narrative Thought World, 2.

62 Petersen, Rediscovering, 49.

63 Petersen, Rediscovering, 67. 
Versorgung mit Nahrung anzusiedeln haben. Dasselbe gilt für Ausscheidungen. Letztere werden auch in fiktionalen Erzählungen recht selten explizit geschildert, sind in der fiktiven Welt aber vorausgesetzt, wie etwa die in den verschiedenen Harry Potter-Bänden wichtige Rollen spielenden Toiletten zeigen. ${ }^{64}$

Auch die Auflösung, mit welcher die Grenzen „eines“ Ereignisses festgelegt werden, erscheinen sehr willkürlich. Weshalb wird etwa zwischen der Rücksendung des Onesimus (Ereignis 6) und der Sendung des Briefes (Ereignis 7) differenziert, als implizites Gegenstück jedoch nur ein Ereignis (8: „both the arrival of Onesimus and the letter at Philemons house“) angenommen?65 Überhaupt ist natürlich auch die Abfassung des Briefes vorausgesetzt - und bei dieser handelt es sich wiederum um ein sehr komplexes Geschehen, das man auch in viele Einzelereignisse aufgegliedert erzählen könnte. ${ }^{66}$ Dasselbe gilt natürlich für die eigentliche Überbringung des Briefes, wie etwa Gooders ausführliche narrative Ausgestaltung des Aufenthalts der Phoebe in Rom zeigt. ${ }^{67}$

Letztlich erfolgt also bereits der Zugriff auf die Einzelereignisse der erzählten fiktiven/realen Welt durch bestimmte Verben (und ihre Nuancierung durch die Wahl des Aspekts) vor dem Hintergrund bestimmter Interessen. Dasselbe gilt für die Auswahl der letztlich als „relevant“ erachteten Ereignisrepräsentationen.

So findet sich auch bei Wright eine ganz ähnliche Bewegung wie bei Witherington: Einerseits schreibt er, dass es möglich sei, „to construct from the Pauline corpus a narrative world of Paul's life and experience. "68 Andererseits entspricht die von ihm grob skizzierte referentielle Sequenz dann allerdings gerade nicht einer neutralen Aneinanderreihung dieser Erlebnisse, sondern nimmt Einteilungen und Schwerpunktsetzungen im Hinblick auf die gesamten Lebenswirklichkeit des Apostels vor:

\footnotetext{
64 Dass manche Enthüllungen von Erzählern über die von ihnen geschaffenen fiktiven Welten allerdings auch über das hinausgehen, was man als Leser ohnehin vom Weltwissen her erschlossen hätte, zeigt gerade, was Rowling, „Chamber of Secrets“ in dieser Hinsicht verlauten ließ: Toiletten seien in Hogwarts erst im 18. Jahrhundert installiert worden und stellten eine Imitation der Erfindung der Muggles dar: „hitherto they simply relieved themselves wherever they stood, and vanished the evidence."

65 Petersen, Rediscovering, 67.

66 Siehe oben, Kapitel 3, Abschnitt 3.4.3.3 zum Grundproblem der Einteilung in Ereignisse und Kapitel 6, Abschnitt 1.5.5 zu konventionalisierten Konzeptualisierungen. Vgl. auch Kapitel 4, Abschnitt 2 zum Ablauf der paulinischen Briefproduktion und Kapitel 9, Abschnitt 3.4 zu verschiedenen Phasen der Textproduktion generell.

67 Gooder, Phoebe.

68 Wright, New Testament, 404.
} 
Such a referential sequence would move from his upbringing as a Pharisee, through his call/conversion, to his missionary and pastoral work, with its attendant suffering ...

Wenn er von einem „level“ spricht, auf dem dieses „personal narrative“ angesiedelt sei und dies mit der Standardgeschichte eines frommen Pharisäers vergleicht, ${ }^{69}$ dann ist eine solche Betrachtungsweise der Gesamtheit der auf Paulus bezogenen Ereignisse von einem ganz bestimmten Vorverständnis des Plots abhängig, also von der Voraussetzung, die Ereignisse unter dem Gesichtspunkt einer pharisäischen Biographie - vielleicht vergleichbar zu Josephus' Vita - auszuwerten.

Ein solches Plot-geleitetes Verfahren der Auswahl und Kombination an Ereignissen unterscheidet sich also letztlich doch elementar von der Edition einer vollständigen - lediglich noch nicht gebundenen - Erzählung eines verstorbenen Schriftstellers! Aber nicht nur die Schöpfung eines umfangreicheren Handlungsstrangs ist aus den besagten Gründen problematisch. Auch die Synthese verschiedener Aussagen zum selben Geschehen der fiktiven/realen Welt erscheint vor diesem Hintergrund sehr fragwürdig.

Schließlich erfolgt auch schon der Zugriff auf das Einzelereignis in einer Erzählung unter der Voraussetzung einer narrativen Strukturierung der dargestellten Geschehnisse. Aus diesem Grund kann letztlich ja auch die Aufgabe des Historikers auch nicht einfach in der Aneinanderreihung von Ereignisbeschreibungen bei verschiedenen Autoren bestehen, als wäre deren Verhältnis zur Realität überall gleichartig gestaltet. ${ }^{70}$ Dasselbe gilt aber eben auch bereits im Hinblick auf einen einzelnen Autoren/Sprecher: Zwei Erzählungen über dasselbe Geschehen können in Abhängigkeit von den Anfordernissen, welche die jeweilige Kommunikationssituation an den Äußerungsakt stellt (Kommunikationsintention, ästhetische Interessen etc.) völlig verschiedene Einteilungen desselben Stücks Wirklichkeit vornehmen.

Das gilt sowohl für die sprachliche Bezugnahme auf einzelne Handlungen $^{71}$ als auch für deren Beziehungen untereinander. So können Erzähler/-innen etwa unterschiedliche Ereignisse als „Ursachen“ anführen, je nachdem, wie weit die gewählte Perspektive eingestellt ist. ${ }^{72}$ Auch das „Rohmaterial“ des hier kritisierten Typs an Konstruktionen ist also bereits durch den jeweiligen

69 Wright, New Testament, 404-405.

70 Vgl. Day, Philosophy of History, 16-20.

71 Vgl. Kapitel 3, Abschnitt 3.4.3.3. Siehe aber auch eine zumindest näherungsweise Klärung mit Blick auf konventionalisierte Konzeptualisierungen von Situationen in Kapitel 6, Abschnitt 1.5.5. 72 Siehe Heilig und Heilig, „Historical Methodology,“ 121-125 zum Zusammenhang von Kausalität und Erklärung. Vgl. zu Kausalität im Rahmen der Beschreibung von Erzählungen Köppe und Kind, Erzähltheorie, 51-52. 
Erzählakt geformt, welchem wir ihn entnehmen - sei dieser nun sprachlich oder mental. Es ist daher auch nicht legitim, die verschiedenen sprachlichen oder simuliert-sprachlichen Repräsentationen von Ereignissen allein auf der Grundlage einer gemeinsamen Referenz zu einer Erzählung zu kombinieren und diese dann dem Autor unserer Quellen zuzuschieben. Möglich ist lediglich, auf dieser Grundlage ein eigenes Narrativ zu bilden - wobei wir entsprechend unserer eigenen Interessen und Schwerpunktsetzungen zahlreiche Modifikationen im Zugriff auf die Ereignisse und deren Verknüpfung vornehmen werden. Von einer Erzählung „des Paulus“ kann hierbei dann aber nicht mehr sinnvoll die Rede sein - beziehungsweise es dürfen dann an dieses Konstrukt keine Kategorien herangetragen werden, welche die kreative Eigenleistung des Apostels voraussetzen würden.

\subsubsection{Paulus als Kritiker unserer Erzählungen?}

Theoretisch denkbar bliebe dann lediglich noch eine Variation dieses Rettungsversuches, die zwar einräumte, dass Paulus bestimmte Ereignisse wohl nie selbst mental miteinander in Beziehung gebracht haben dürfte, dass er aber, wenn man sie ihm verknüpft vorgestellt hätte, dieser Erzählung wohl beigepflichtet hätte. Allerdings würde Paulus im Rahmen eines solchen Vorgehens dann nicht mehr „als Erzähler“ behandelt, sondern viel eher als Kritiker unserer eigenen Erzählungen.

Dies wäre dann in etwa der Situation vergleichbar, dass einer heute lebenden prominenten Person von einem Autor eine verfasste Biographie zur „Autorisierung“ vorgelegt würde (nur dass Paulus eben nicht mehr nach seiner Meinung gefragt werden kann). Die Möglichkeit, dass sich jemand in einem Werk über sein Leben wiedererkennen mag, ändert allerdings doch nichts daran, dass diese Person die betreffende Geschichte so nicht selbst erzählt hätte, denn es besteht ein fundamentaler Unterschied zwischen einer Erzählung, die eine Person abzusegnen bereit wäre und einer solchen, die sie selbst erzählt oder zu erzählen simuliert. Selbst wenn wir voraussetzen, der Autor hätte im Hinblick auf die Verbindung einzelner Ereignisse in jedem Fall genau diejenige Verknüpfung hergestellt, die auch der Prominente bei eigenständigem, aber eben nicht stattgefunden habendem Überlegen postuliert hätte, ändert dies doch nichts an der signifikanten Tatsache, dass dieser eben keine Biographie verfasst hat (noch sich in einem mentalen Akt vorgestellt hat, seine Lebensgeschichte als Ganzes zu erzählen).

Wenn man bereits ist, das Konzept des ,Erzählaktes“ im Interesse der Machbarkeit einer einheitlichen Erzählung bei Paulus soweit aufzuweichen, könnte man auch gleich den Ruhm für die „potenzielle Verfasserschaft“ von 
Literaturklassikern für sich beanspruchen, da damit das Konzept des Autors ad absurdum geführt wäre. ${ }^{73}$

Der Verweis auf die bloße Kontinuität der erzählten Welt verschiedener paulinischer Protonarrative kann daher letztlich kein befriedigendes Kriterium für die Gesamtsynthese darstellen. Das im folgenden Abschnitt dargestellte aufwendigere und mit mehr Unsicherheiten verbundene Verfahren, dessen Ergebnis daher auch mit mehr Zurückhaltung vertreten werden müsste, scheint daher unumgänglich.

\section{Leitlinien für die Synthese}

\subsection{Orientierung an der Textfolge}

Methodisch führt daher kein Weg daran vorbei, zunächst die Produkte konkreter Äußerungsakte dem Prozess ihrer Äußerung entsprechend - d. h. Chronologie und Distanz im Text wahrnehmend - zu analysieren: Wenn im Umkreis einer expliziten Erzählung (d.h. durch nicht-narrative textuelle Elemente von dieser getrennt) weitere Ereignis-Bezüge ausgemacht werden können, dann sollte der Frage nachgegangen werden, inwiefern der Akt des Erzählens über die konkrete narrative Vertextung hinaus im Text eventuell seine Spuren hinterlassen haben könnte. Ebenso gilt, dass im Falle des Fehlens eines expliziten narrativen Bezugspunktes - also in Fällen, in welchen wir keine explizite Erzählung als Ausgangspunkt unserer Untersuchung haben - primär der Frage nachzugehen ist, wie in unmittelbarer Nachbarschaft auftauchende Ereignis-Bezüge eventuell miteinander in Verbindung stehen könnten.

Wie der Nachweis einer solchen Zusammengehörigkeit erfolgen kann, wurde oben (Kapitel 9, Abschnitt 5) am Beispiel von Gal 4,1-2, 3-6, 8-10 und 11-12 demonstriert. Auch in 2. Thess 3 lassen sich anhand verschiedenartiger sprachlicher Phänomene Protonarrative identifizieren, die ein zusammengehöriges Ganzes zu ergeben scheinen und in diesem Zusammenhang den Diskurs stützen. ${ }^{74}$

73 Die Buddenbrooks hätte ich schließlich, das Gegenteil kann man mir kaum nachweisen, exakt so verfasst, wie Thomas Mann das tat, wenn ich mich nur dazu entschlossen hätte, das auch zu tun.

74 Siehe grundsätzlich Kapitel 11, Abschnitt 2 zu den Protonarrativen auf verschiedenen Erzählebenen und der Rolle von Vorausdeutungen in 2. Thess 3,7b-8 und Kapitel 12, Abschnitt 2.3.2 zum Verhältnis von Diserzähltem und Erzähltem in diesen beiden Versen. Vgl. dann zur Funk- 
Für die weitere empirische Prüfung des heuristischen Potenzials der narratologischen Perspektive auf die Paulusbriefe wäre es daher angezeigt, implizite Erzählungen nicht mehr aufgrund von als Konstante des Handlungsstrangs vorausgesetzten Erzählfiguren zu bilden, sondern konkrete Texte - am besten ganze Briefe - auf die in der Textfolge tatsächlich (fragmentarisch) zum Ausdruck kommenden Protoerzählungen hin zu untersuchen. Die recht systematische Übersicht, die zumindest hinsichtlich verneinter (Kapitel 12) und futurischer Ereignisbezüge gegeben wurde (Kapitel 13 und 14) dürfte dafür eine gewisse Hilfestellung darstellen. Die Frage, welche „Rolle(n)“ einzelne Personen oder Entitäten in den paulinischen Erzählungen spielen, kann dann im Anschluss gestellt werden.

Es sollte zum Abschluss dieses kritischen Abschnittes noch betont werden, dass die oben zitierten rekonstruierten Protoerzählungen sich natürlich im Regelfall einer intensiven Beschäftigung mit einzelnen Perikopen verdanken. Die auf einzelne Figuren bezogene Präsentation muss daher natürlich nicht mit einer solchen Analyse einhergehen. Dann jedoch wäre auch zu erwarten, dass die exegetische Forschungsliteratur diese kleinteiligere Analyse auch irgendwo dokumentiert. Sie scheint in der Praxis aber vielmehr vorausgesetzt und kann damit schlecht überprüft werden. Und zumindest in einigen Fällen (z. B. in Narrative Dynamics) tritt die figurenbezogene Rekonstruktion von Handlungssträngen eindeutig als methodische Vorgabe auf.

\subsection{Optionen für die umfassendere Zusammenschau}

\subsubsection{Hinführung}

Sollte in der Zukunft eine entsprechende Analyse für ganze Schriftstücke - oder sogar das corpus Paulinum als Ganzes - vorliegen, könnte man dann natürlich eine Anschlussfrage stellen: Können diese Ereigniszusammenhänge nun auf irgendeine Weise miteinander verbunden werden, sodass man im Resultat eventuell doch noch bei dem von Wright postulierten umfassend(er)en Narrativ landen würde? Um diese Frage zu beantworten, muss geklärt werden, auf welche Weise verschiedene Ereignisverbünde in einer Erzählung zusammengehören können. Hier sind mehrere grundsätzlich verschiedene Möglichkeiten zu berücksichtigen.

tion im größeren Abschnitt 3,4-12 vor allem Kapitel 14, Abschnitt 4.4.3.6. Vgl. auch im selben Kapitel Abschnitt 3.4.3 zu 2. Thess 3,4 und 4.4.31 zu 2. Thess 3,12. 


\subsubsection{Aufeinander folgende Handlungsphasen oder Erzählakte?}

Die nächstliegende Option ist zunächst diejenige, dass es sich bei mehreren, zunächst als separat erscheinenden Handlungen letztlich um zusammengehörige Handlungsphasen ${ }^{75}$ handelt, dass also im Sinne der Sequenz des Plots eine Nebenordnung möglich ist.

In diesem Fall unterscheidet sich das Vorgehen in der Analyse nicht grundsätzlich von der Überprüfung des Zusammenhangs einzelner Ereignisse, nur dass nun größere Komplexe miteinander in Beziehung gesetzt werden. Auch hier muss jedoch sorgfältig unterschieden werden: Haben wir es wirklich mit (a) einer erzählten Sequenz von Ereignissen zu tun oder nur (b) mit einer Abfolge von zu unterscheidenden Erzählakten über Ereignisse, die eben zufälligerweise auch in der Wirklichkeit aufeinander folgen?

Die erste Situation liegt vor, wenn der simulierte Erzählakt unterbrochen und später wieder aufgenommen wird, ganz so, wie dies auch beim expliziten Erzählen der Fall sein kann (vgl. unten, Abschnitt 5, zu 2. Kor 2,13 und 7,5). Der zweite Fall setzt voraus, dass die Handlung der ersten Erzählung zu ihrem Abschluss gekommen ist, bevor erneut erzählend eingesetzt wird.

Auch wenn man Wright daher in seinem Verständnis von Röm 6-8 folgte, könnte man die Frage aufwerfen, ob die Verbindung mit der in Röm 4 zur Sprache kommenden „früheren“ Episode angebracht ist - oder ob Paulus hier schlicht mit zwei (Proto-)Narrativen auf in der realen Welt aufeinander folgende Geschehenszusammenhänge eingeht (insbesondere, da Adam in Röm 5 die Chronologie ${ }^{76}$ ja zu durchbrechen scheint).

Um begründet zwischen den beiden Fällen unterscheiden zu können, ist vor allem auf den narrationsspezifischen Vorgang des „Abschließens“ zu achten (siehe oben, Kapitel 8, Abschnitt 5.2.3). Bei Sammlungen gedruckter Erzählungen

75 Zuweilen wird in der Unterscheidung von Bestandteilen von Handlungen differenziert zwischen Einheiten, die „nur dynamische Aussagen“ aufweisen und solchen, die „dynamische und statische Aussagen zusammen“ enthalten (so Finnern und Rüggemeier, Methoden, 223:

\begin{tabular}{lll}
\hline Erzählabschnitt & nur dynamische Aussagen & $\begin{array}{l}\text { dynamische und statisch Aussagen } \\
\text { zusammen }\end{array}$ \\
\hline kleinste Einheit & Ereignis & Aussage \\
\hline größere Einheit & Handlungsphase & Geschehen (Szene) \\
\hline große Einheit & Handlungssequenz & Episode (Akt) \\
\hline Ganze Einheit & Handlung & Geschichte \\
\hline
\end{tabular}

Auch Finnern und Rüggemeier unterschreiben diese Tabelle jedoch mit „Bestandteile einer Handlung und ihre Bezeichnung“ (Hervorhebung nicht im Original).

76 Natürlich dürfen Protonarrative ebenso wie explizite Erzählungen auch Analepsen aufweisen. 
wird dieser etwa durch den Seitenumbruch oder sogar durch die „Lexikalisierung des Abschlusses,“ durch das Wörtchen „Ende,“ angezeigt. ${ }^{77}$ Auch im Medium der Mündlichkeit stehen spezifische Mittel zur Verfügung, die teilweise auch literarisch imitiert werden. ${ }^{78}$ Die Überleitung von der „Erzählwelt zur Sprechsituation“ in einer mündlichen Konversation markiert darüber hinaus einen Schnitt, ${ }^{79}$ welcher im Fall eines erneuten Erzähleinstiegs daher im Regelfall die erneute Thematisierung fordert. ${ }^{80}$

Vor diesem Hintergrund fällt etwa die geringe Markierung des Neuansatzes in Gal 4,8 auf. Hier markiert lediglich das $\alpha \lambda \lambda \alpha \dot{\alpha}$ einen Übergang. Eventuell könnte man in diesem kleinen Formelement noch am ehesten die Darstellung der Formrelevanz geboten sehen: Nach dem vorläufigen Ende der Erzählung 4,3-6 aufgrund der argumentativen Vertextung in 4,7 kommt nun etwas, das in einem Kontrast zum bisher Gesagten steht - es ist zwar nicht notwendig, aber doch naheliegend, dass es sich bei diesem „Etwas“ nun wieder um eine Erzählung handelt. Während aber in Gal 4,1-2 und 4,3 eine explizite Thematisierung und dann Überleitung (oü $\omega \varsigma$ ) zur konkret ins Auge gefassten Erzählfigur (,wir“) vorgenommen wird, knüpft Gal 4,8 direkt wieder an das „Damals“ ( gesamten Text liegt also wohl tendenziell eher ein einziger mentaler Erzählakt zugrunde. Diese Schlussfolgerung wird auch dadurch gestärkt, dass in diesem Fall kaum die Gefahr besteht, eine Sequenz in der realen Welt mit einer temporalen Ordnung in einer Erzählung zu verwechseln: Denn Gal 4,8 setzt ja eindeutig nicht zu einem gegenüber 4,6 späteren Zeitpunkt ein.

Relativ betrachtet einfach ist eine solche Entscheidung meist dann, wenn ein Text mit einer informierenden Intention verfasst wurde. ${ }^{81}$ Nicht selten zeigen dann explizite Leseanweisungen an, ob die bis zu einem gewissen Punkt gelieferte Information bereits das darstellt, was erzählend kommuniziert werden sollte. Mustergültig demonstriert dies wieder der Brief in Queneaus Stilübungen: ${ }^{82}$

77 Gülich und Hausendorf, „Vertextungsmuster Narration,“ 380.

78 Gülich und Hausendorf, „Vertextungsmuster Narration,“ 380.

79 Gülich und Hausendorf, „Vertextungsmuster Narration,“ 381.

80 Vgl. zur Thematisierung Heinemann, Gülich und Hausendorf, „Vertextungsmuster Narration, “ 378-379.

81 Zur Kommunikationsintention vgl. oben Kapitel 8, Abschnitt 4. Auch Briefe können als Folge einer solchen Zielsetzung und eines geeigneten Gegenstandes explizit als primär narrative Vertextungen auftreten. Vgl. Queneaus Brief in den Stilübungen (S. 139): „Mein lieber Totor, ich ergreife heute die Feder statt den Pflug, um Dir mitzuteilen, dass ich Dir also einen Brief schreibe, um Dich von meinen neusten und guten Neuigkeiten zu unterrichten." Siehe oben, Kapitel 1, Abschnitt 3.5.3 zur Kommunikationsintention von Brieftextsorten und Kapitel 8, Abschnitt 5.2.2.2 zur damit einhergehenden Bearbeitung narrationsspezifischer Aufgaben im Brief.

82 Queneau, Stilübungen, 139 (Hervorhebung nicht im Original). 
Stell Dir vor, ich wollte Tante Hortense besuchen, und weil sie ja drüben wohn, nahm ich den S-Bus, der da drüben hinfährt. Ich blieb auf der Plattform, um mir die wirklich schöne Landschaft anzuschauen, die an meinen verwunderten Augen vorbeizog. Aber ich bin mit meiner Geschichte noch nicht fertig.

Fehlt ein solcher Hinweis, so bleibt oft keine andere Wahl, als aufgrund der Plot-Struktur zu erwägen, ob der Spannungsbogen in einem bestimmten Textausschnitt bereits „komplettiert“ vorliegt (vgl. für ein Beispiel oben, Kapitel 16, Abschnitt $4.2 \mathrm{zu}$ 2. Kor 2,12-13). 83

Im Fall von Protoerzählungen muss allerdings natürlich immer mit der Möglichkeit gerechnet werden, dass uns die entscheidenden Indikatoren fehlen, um zu beurteilen, ob der Autor

(a) die fragmentarisch an die Textoberfläche dringenden Erzählzüge als Einheit vor Augen hatte,

(b) es sich um einen erzählerischen Neusansatz handelt, der jedoch chronologisch an die vorangegangene Erzählung anknüpft (eine „Fortsetzung,“ wie sie auch im literarischen Bereich üblich ist oder mündlich angezeigt werden kann durch Formulierungen wie: „Und was dann geschah, muss ich auch noch erzählen ... “; oder oben im Briefbeispiel: „Aber ich bin mit meiner Geschichte noch nicht fertig ... “), ${ }^{84}$

(c) eine thematische Verknüpfung mehrerer Erzählungen vorliegt, die jedoch nicht impliziert, dass aus dem jeweils Erzählten ein zusammengehöriger Plot zu bilden ist (,Wo wir gerade vom ,Lebensmittelvergiftungen“ sprechen ... ") oder

(d) der Autor gerade einen unbewussten oder sogar bewussten (etwa weil sich das Protonarrativ doch nicht als für die Situation passend erweist) narrativen Neueinsatz wählt.

Im Fall (a) wäre ein Verständnis der Ereigniszusammenhänge als sich ergänzende Handlungsphasen angezeigt, im Fall (b) zumindest unter der Voraussetzung, dass die relative Eigenständigkeit der Erzählakte angemessen berücksichtigt wird.

\subsubsection{Repetitives Erzählen derselben Handlungsphase und separate Erzählakte} Wenn in einem Text mehrfach auf dieselben Geschehnisse Bezug genommen wird, scheidet die Möglichkeit, die verschiedenen Abschnitte zu einer

83 Vgl. Kapitel 3, Abschnitt 3.4.4.3. Natürlich gibt es keinen Zwang, eine Erzählung auch vollständig „gehaltvoll“ zu präsentieren (vgl. Kapitel 9, Abschnitt $4 \mathrm{zu}$ „unvollständigen“ Plots). Man muss daher vorsichtig sein, wenn man eine unvollständige (Proto-)Erzählung aufgrund der Voraussetzung eines geschlossenen Spannungsbogens komplettiert. Dies gilt umso mehr, wenn keine vollständige Narrativisierung stattgefunden hat: Nicht alle narratologischen Konzepte eignen sich zur Beschreibung von Entitäten, welche Vorstufen von Erzählen darstellen.

84 Siehe auch oben, Kapitel 4, Abschnitt 8.2.4.3 zu den Diskursmarkern (v. a. „Metakonversationsmarkern“), die in dieser Hinsicht für die Koine noch sorgfältiger auszuwerten sind. 
umfangreicheren Erzählung reihend zusammenzufügen aus. Die Versuchung einer Synthese erscheint dennoch oft groß, vor allem, wenn die vorliegenden Erzählungen jeweils Elemente aufweisen, welche sonst fehlen. Nicht immer ist es jedoch legitim, die Aussagen zusammenzustellen, um so den im Text je nur fragmentarisch zugänglichen Plot durch die Parallele „aufzufüllen.“

Denn wie oben bereits angemerkt wurde (Abschnitt 2.4), ist die Eigenständigkeit verschiedener Erzählakte gerade dann wahrzunehmen, wenn auf denselben Ausschnitt der Realität Bezug genommen wird. Ereigniseinteilungen (vgl. oben, Abschnitt 3.3.3 mit weiteren Verweisen) können in separaten Erzählakten unterschiedlich vorgenommen werden, sodass es ein Trugschluss wäre, anzunehmen, ein in einem Fall enthaltenes Ereignis müsse auch Bestandteil des Plots im anderen Fall sein.

Es mag daher zwar in solchen Fällen aufgrund der gemeinsamen Referenz möglich sein, in einer Wiedergabe des semantischen Gehalts der beiden Protoerzählungen in eigenen Worten, einen einzigen Plot für durch mehrere simulierte Erzählakte mental produzierte Erzählungen zu entwerfen, doch daraus lässt sich eben nicht zwangsläufig ableiten, dass ein bestimmter Ausschnitt der Wirklichkeit auch in der (mentalen) Repräsentation beider Protoerzählungen vertreten sein muss. Man muss sich also davor hüten, Fragmente einer Protoerzählung allein aufgrund eines Bezugs auf dieselben Geschehnisse an einer anderen Stelle in die Rekonstruktion einzutragen. Diese Anfrage betrifft natürlich auch Hays' Kombination der verschiedenen Elemente in Gal 3,13-14 und Gal 4,3-6.

Zugleich muss an dieser Stelle auch auf einen Sonderfall verwiesen werden, der in der Tat ein Potenzial für die Rekonstruktion aufweist. Denn es besteht durchaus die Möglichkeit, dass innerhalb eines einzigen Erzählaktes mehrfach auf einen Ereigniszusammenhang der Wirklichkeit rekurriert wird. ${ }^{85}$ Bei aller Vorsicht im Umgang mit der Synthese von Aussagen zu denselben Geschehnissen ist also umgekehrt durchaus die Möglichkeit festzuhalten, dass mehrfache Thematisierung und Dramatisierung doch zum selben Erzählakt gerechnet werden kann.

Für die Erhebung der Handlung - im Sinne der chronologischen Abfolge und sinnhaften Verknüpfung der zentralen Ereignisse - ist durch die Identifizierung eines solchen Falles des Gestaltungsmittels des „,repetitiven“ Erzählens jedoch im

85 Für wiederholte explizite Erzählungen innerhalb derselben Konversation siehe Heller, Morek und Quasthoff, „Mehrfaches Erzählen“ mit einer sehr differenzierten Antwort auf folgende Frage: „Warum wird eine Geschichte im selben Gespräch zweimal erzählt?“ Siehe grundsätzlich oben, Kapitel 3, Abschnitt 4.2 zur Abgrenzung vom repetitiven Erzählen. Siehe auch Kapitel 9, Abschnitt 5.4.1 und Kapitel 16, Abschnitt 3 zum Verhältnis von Gal 4,3-6 und 4,8-9. 
Normalfall wenig gewonnen. ${ }^{86}$ Insofern tatsächlich nur etwas „wiederholt“ wird, wird dem Erzählten schließlich nichts Neues hinzugefügt. Bereits im Kontext der „Mehrfachbearbeitungen“ von narrationsspezifischen Aufgaben wurde darauf hingewiesen, dass durch solche Erzähltechniken nicht das Erzählte modifiziert wird, sondern das Erzählen als Akt selbst in das Zentrum des Interesses rückt (siehe oben, Kapitel 8, Abschnitt $5.5 \mathrm{zu}$ 2. Kor 12,1-6).

Etwas anders sieht die Situation freilich dann aus, wenn durch die erneute Schilderung eine Revidierung oder Ergänzung der ersten Version erfolgt, etwa wenn eine neue Perspektive eingenommen wird, die Zugang zu bisher ,übersehenen“ Aspekten des Geschehens hat (vgl. oben zu Gal 4,9a), oder der Erzähler im ersten Lauf „unzuverlässig“ erzählt hat und nun eine angemessenere Version bietet (vgl. oben zu Gal 4,9b-11). ${ }^{87}$

\subsubsection{Verschiedene Handlungsstränge derselben Erzählung?}

Neben der Möglichkeit, dass einzelne Ereigniszusammenhänge sequentielle Ausschnitte eines einzigen Plots darstellen oder aber denselben Ausschnitt repetitiv aufgreifen, muss auch mit der Möglichkeit gerechnet werden, dass die Ereignisbezüge auf verschiedene Handlungsstränge ein und derselben Erzählung zurückzuführen sind.

Dabei ist zu beachten, dass diese zugrundeliegenden Handlungsstränge temporal natürlich durchaus überlappen können. ${ }^{88}$ Die wiederholte Thematisierung desselben Zeitpunktes ist daher nicht auf die Optionen „separate Erzählungen“ und „repetitives Erzählen“ beschränkt, sondern kann auch parallel verlaufende Handlungen betreffen.

Wie oben (Kapitel 3, Abschnitt 5.3) bereits angesprochen, ergibt sich der Zusammenhang einer Ereignisfolge hierbei meist durch die Fokussierung auf die „Handlungen und Erlebnisse einer Figur."89 Auch wenn dies ein Phänomen ist, das insbesondere in umfangreicheren Erzählwerken begegnet, ${ }^{90}$ kann es auch im mündlichen Diskurs erscheinen. ${ }^{91}$

86 Vgl. Köppe und Kindt, Erzähltheorie, 189-190.

87 Zur Bandbreite des unzuverlässigen Erzählens vgl. Köppe und Kindt, Erzähltheorie, 236-256.

88 Vgl. Köppe und Kindt, Erzähltheorie, 108.

89 Um wieder das Beispiel eines Gesprächs bei einem gesellschaftlichen Anlass zu bemühen: Es ist möglich, dass der Ehemann von dem gemeinsamen Urlaub mit seiner Frau berichtet und dabei zwei Plots parallel narrativ entfaltet, die sich unter Umständen (bei vielen eigenständigen Unternehmungen) recht frei entwickeln können, auch wenn sie durch Handlungsort und zwischenzeitliche Interaktion verbunden sind.

90 Siehe hierzu Köppe und Kindt, Erzähltheorie, 108.

91 Zur Verbindung von Handlungssträngen siehe Köppe und Kindt, Erzähltheorie, 108-109. 
Die Behauptung, dass zwei in einem Text identifizierte Ereignisfolgen als Teile verschiedener Handlungsstränge desselben Protonarrativs zu verstehen sind, stellt vermutlich den umstrittensten Punkt in der Rekonstruktion umfassender Protoerzählungen dar. Zumindest im kleineren Umfang (etwa in der Analyse zu Röm 15; vgl. Kapitel 11, Abschnitt 8) ist dieses Phänomen im Laufe dieser Arbeit allerdings bereits begegnet.

\subsubsection{Erzählungen verschiedener Ebenen}

Die bisher genannten Optionen für den Zusammenhang mehrerer Ereignisverbünde setzen voraus, dass die erzählerisch herausgegriffenen Ereignisfolgen auf derselben narrativen Ebene anzusiedeln sind.92 Erzählungen (egal ob fiktional oder nicht) verfügen immer über mindestens eine Ebene. ${ }^{93}$ Eine Erzählung kann jedoch auch den Rahmen für eine in ihr geschilderte Binnenerzählung bilden. Theoretisch wäre also auch denkbar, das Fragment eines Protonarrativs als in ein anderes Protonarrativ eingebettete Erzählebene zu begreifen.

Wie im Hinblick auf Gal 1-2 vor dem Hintergrund des paulinischen Erzählstils bereits deutlich wurde ${ }^{94}$ sind die hier begegnenden Binnenerzählungen bei Paulus in explizit narrativ vertexteten Abschnitten recht selten. Im Umgang mit Protoerzählungen dürfte die Kategorie eine noch geringere Rolle spielen. Am ehesten wäre noch denkbar, dass wir es bei zitierten Traditionen mit Fragmenten wörtlicher Figurenrede zu tun haben könnten, die als Teil eines im Hintergrund stehenden mentalen Narrativs aufgerufen werden.

Der Nachweis dürfte im Einzelnen jedoch sehr schwierig sein, schwieriger noch als dies für den Nachweis von Traditionsgut im Allgemeinen gilt. Die These, dass etwa in Gal 1,4 letztlich die Erzählung über die erzählenden Gegner zugrunde liegt, kann zumindest am Text selbst nicht mehr bestätigt werden (vgl. zu dieser Position Kapitel 14, Abschnitt, 5.3.2.6). Lediglich im Hinblick auf passive Prognosen und Pläne von Erzählfiguren (vgl. etwa zu 2. Thess 3,7b-8 in Kapitel 11, Abschnitt 2) lässt sich einigermaßen zuverlässig von „Binnen-Protoerzählungen“ sprechen. Die Identifizierung direkter Rede in Protoerzählungen ist demgegenüber viel schwieriger. Siehe allerdings auch die Diskussion (Kapitel 11,

92 Vgl. zu diesem Abschnitt Köppe und Kindt, Erzähltheorie, 161-173.

93 Unter der Annahme Genettes, dass jede fiktionale Erzählung über einen fiktiven Erzähler verfüge, ergäbe sich allein schon aufgrund dieser Rahmenhandlung des (unterschiedlich explizit erzählten) Erzählens eine Ebene, sodass für solche Erzählungen anzunehmen wäre, dass sie mindestens zwei Erzählungen aufwiesen. Die Vorannahme ist jedoch sehr problematisch. Vgl. Kapitel 3, Abschnitt 5.2.

94 Vgl. Kapitel 5, Abschnitt 5.1.2.2 zu Gal 1,13-14 (vgl. kurz in Kapitel 5, Abschnitt 3.6) und Kapitel 5, Abschnitt 3.8 sowie Kapitel 7, Abschnitt 5.2.1.2 zu Gal 1,23. 
Abschnitt 8.3) zu Röm 15,21 und (Kapitel 12, Abschnitt 3.2) zu Röm 10,15, wo man unter Umständen Zitate (innerer) Monologe ausmachen könnte.

Auch wenn die Kategorie in der Synthese eine eher geringe Rolle spielen dürfte, soll sie hier zumindest erwähnt werden, weil gerade bei Wright häufiger von „Einbettung“ die Rede ist, damit aber - wie unten der Abschnitt 5.2 zeigt etwas völlig anderes gemeint ist. Dieser Aspekt wird im folgenden Abschnitt zur Sprache kommen, in welchem nun das konkrete Gepräge des von Wright postulierten umfassenden impliziten Weltanschauungs-Narrativs diskutiert werden soll.

\section{Die Gestalt des „larger implicit narrative“ von N. T. Wright}

\subsection{Drei „stories“ - eine komplexe Verbindung?}

Wright widmet das gesamte Kapitel 7 in Paul and the Faithfulness of God der Explikation dessen, was er sich unter der weltanschaulichen Erzählung des Paulus vorstellt. Im Ausblick des vorangehenden Kapitels beschreibt er es als „a complex and integrated multiple narrative“95 und im Anschlusskapitel nimmt er auf seine Rekonstruktion der „complex implicit interlocking narratives“96 Bezug. Doch wie genau sollen wir uns diese Komplexität ${ }^{97}$ der Erzählung vorstellen?

Der fließende Übergang von Singular zu Plural (,,integrated multiple narrative“... ,,interlocking narratives“) deutet bereits an, was im Mittelpunkt steht: der nicht gerade simple Zusammenhang verschiedener Ereignisfolgen. Wright selbst charakterisiert diesen an zentraler Stelle wie folgt: ${ }^{98}$

There are, after all, several „stories“ which are commonly thus detected within the implicit worldview of the apostle Paul ... I shall now suggest that these various stories do actually have a coherent interlocking shape, nesting within one another like the sub-plots in a play.

Bei diesen verschiedenen „stories“ (wir werden im Folgenden im Anschluss an Wright vorerst ebenfalls von für sich stehenden „Erzählungen“ sprechen und später darauf eingehen, ob dies sinnvoll ist; siehe unten, Abschnitt 5.4) handelt es sich erstens um die „overall story of the creator God and the cosmos. “99 Dieses

95 Wright, Faithfulness, 454.

96 Wright, Faithfulness, 562.

97 Wright, Faithfulness, 499: , ... complex story ... “; S. 505: „... Paul’s complex narrative world ... “; S. 521: „... implicit complex narrative ... complex narrative ... “

98 Wright, Faithfulness, 474.

99 Wright, Faithfulness, 475. 
Narrativ weise einen Plot auf, „[which] frames all the sub-plots that constitute the more obvious and immediate subject-matter of Paul's writing. “100

Wright spricht von dieser Erzählung auch als dem „overarching narrative“101 und dem „main plot,“ in welchen ein „main subplot“ und ein „second but vital subplot“ eingebunden seien. ${ }^{102}$ Beim ersten Subplot handelt es sich um ,the story of the human creatures through whom the creator intended to bring order to his world. "103 Der zweite Subplot ist die Erzählung über Israel. ${ }^{104}$

Da Wright hier in der Forschung große Missverständnisse sieht, widmet er einen weiteren Abschnitt der Frage nach der „story of Torah“: Es handle sich dabei nicht um eine eigenständige Erzählung, ${ }^{105}$ sondern vielmehr um ein Element, dem eine wichtige Funktion innerhalb des zweiten Subplots zukomme. ${ }^{106}$ Auch im Hinblick auf Jesus kann nicht im eigentlichen Sinn von einer „eigenständigen“ Erzählung gesprochen werden: „He plays the leading role within all the others. “107 Durch ihn kommen alle drei Erzählungen zu ihrer Auflösung. ${ }^{108}$

Diese Zusammenfassung weist eine eigentümliche Spannung auf: Auf der einen Seite begegnen uns bei Wright anscheinend drei eigenständige Erzählungen, auf der anderen Seite werden ihre Plots als miteinander verbunden dargestellt. Der Schlüssel zum Verständnis liegt in der oben zitierten Formulierung, welche die Erzählung über die Menschheit im Hinblick auf das „overarching narrative“ definiert: Die darin geschilderten Ereignisse treiben in Wrights Sicht letztlich den Hauptplot voran. Ebenso gilt für die Erzählung über Israel, dass die darin enthaltenen Geschehnisse einen „vital effect on the entire action“ hätten. ${ }^{109}$ Während es im Hauptplot um Gottes Absicht gehe, durch die Menschheit (erster Subplot) „his image and glory“ in die Welt scheinen zu lassen, ${ }^{110}$ handle die Geschichte

100 Wright, Faithfulness, 476.

101 Wright, Faithfulness, 477.

102 Wright, Faithfulness, 516.

103 Wright, Faithfulness, 516.

104 Wright, Faithfulness, 495.

105 Wright, Faithfulness, 516: „The ,story of Torah,' then, is comprehensible when, and only when, we see it a part of the story of God's people: not as an independent narrative, not even really as the ,hero' or ,villain' of a comic or tragic narrative of its own, but as the means by which God sheds the bright light both of promise and of warning on Abraham's family, Israel according to the flesh, in their Adamic state.“

106 Wright, Faithfulness, 505. Siehe oben zu Wrights Vorwurf, Exegeten würden die Torah meist dem falschen Subplot zuweisen, Abschnitt 3.2.3.

107 Wright, Faithfulness, 521.

108 Wright, Faithfulness, 517.

109 Wright, Faithfulness, 495.

110 Wright, Faithfulness, 487. 
über das Volk Gottes (zweiter Subplot) davon, wie Gott durch dieses in der übergeordneten Handlung (erster Subplot) für eine Lösung („Errettung“) sorge und damit letztlich auch ermögliche, dass der „ultimate plot“ zu seinem Ziel komme: „the covenant plan for Israel is a vital link in the chain of suplots by which that ultimate plot is resolved." 111

\subsection{Die drei „stories“ und verschiedene Erzählebenen?}

Diese Darstellung scheint intuitiv in der Tat den Aspekt der Zusammengehörigkeit genügend zu begründen. Doch wie kann diese Kohärenz nun in den in Abschnitt 4 erarbeiteten systematischen Kategorien erfasst werden? Anders gesagt: Wie müsste das Resultat einer solchen „Bottom-Up“-Synthese aussehen, um Wrights These $\mathrm{zu}$ bestätigen?

Eine solche Analyse des von Wright gelieferten Entwurfs stellt sich als gar nicht so einfach heraus. $\mathrm{Zu}$ einem nicht geringen Teil mag dies an der von Wright gewählten Analogie liegen, mit welcher er die Verbindung von Haupt- und Subplots erläutert: Shakespeares Sommernachtstraum. ${ }^{112}$ Zwar betont Wright, dass diese Analogie nicht überstrapaziert werden dürfe, ${ }^{113}$ weil Paulus natürlich nicht Dramen verfasst habe. ${ }^{114}$ Und doch bleibt eben der Anspruch, durch die Analyse der Handlung dieser Komödie in die Lage versetzt $\mathrm{zu}$ sein, nun auch die Komplexität der Erzählung(en) bei Paulus zu verstehen, „[being] able to bring some order to the chaos of speculation about the various ,stories" to be found within, underneath or around the edges of Paul's writing." 115

Genau in dieser Hinsicht ergibt sich jedoch eine ganze Reihe von Problemen. So könnte man aus Wrights ausführlicher Darstellung des die Komödie abschließenden „play within the play“116 - der Aufführung der Geschichte von Pyramus und Thisbe im Rahmen der Hochzeit - schließen, dass zumindest eine der von ihm identifizierten Handlungen als eine eingebettete Binnenerzählung innerhalb eines größeren paulinischen Narrativs zu verstehen sei.

Dies ist jedoch sicherlich nicht der Fall: Keine der oben genannten drei Erzählungen wird innerhalb einer der anderen Erzählung erzählt. Dabei ließe sich diese Kategorie durchaus sinnvoll im Hinblick auf Wrights Paulus-Exegese

111 Wright, Faithfulness, 502.

112 Wright, Faithfulness, 468-474.

113 Wright, Faithfulness, 474.

114 Wright, Faithfulness, 473.

115 Wright, Faithfulness, 473. Hervorhebung hinzugefügt.

116 Wright, Faithfulness, 471-473. 
anbringen, allerdings an ganz anderer Stelle: Wenn Wright etwa davon erzählt, wie Paulus der Gemeinde in Korinth einen Ausschnitt seines Protonarrativs präsentierte, haben wir dort (also in Wrights Buch!) zumindest eine Erzählung mit zwei Ebenen. ${ }^{117}$ Ja, da Wright die „story of the church“ zwar von der Ebene der Weltanschauung abhebt, sie aber letztlich doch in Kontinuität mit der Erzählung über Israel sieht, ${ }^{118}$ könnte man Wrights Werk sogar noch eine weitere Binnenerzählung unterstellen, die noch dazu durch eine Metalepse mit der Rahmenhandlung verbunden ist, die etablierten Ebenenbeziehungen also kunstvoll durchbricht: ${ }^{119}$ Paulus erzählt eine Geschichte, in welcher eine Größe eingeführt wird, welcher letztlich auch Wright angehört, welcher wiederum Paulus’ Erzählung paraphrasiert!

Während solche Überlegungen sicherlich ihren Reiz haben, tragen sie für das Verständnis der „Einbettung“ verschiedener paulinischer Erzählungen im Sinne Wrights nichts bei. In dieser Hinsicht ist die Kategorie völlig unbrauchbar und die von Wright gewählte Analogie könnte hier zu falschen Annahmen beim Leser führen.

Diese Gefahr wird leider noch dadurch verstärkt, dass Wright selbst das „play within the play“ in Hinsicht auf Paulus explizit aufgreift - und zwar für die Ereignisse, die mit Jesus zusammenhängen. ${ }^{120}$ Damit sollen diese nun nicht, wie man vermuten könnte, als eine Binnenerzählung klassifiziert werden - vielmehr möchte Wright damit einen Aspekt auf die Jesus-Erzählung übertragen, den er für das Spiel-im-Spiel bei Shakespeare festgehalten hat:121

The ,play within the play ' functions as the key, the final sub-plot, making a subtle and dark sense of all the others, laying to rest, in sharp Romeo-and-Juliet style, the potential tragedies that had hovered over the rest of the drama.

Analog hält er im Hinblick auf Jesus fest:122

[A]nd now we come to the play within the play, the small, close-up story in which the others are resolved. Just as we come down from the heights of royalty (Theseus and Hippolyta) to the group of rustic players rehearsing and then performing their tragic tale of misunderstanding and death, with Moonshine looking on, so Paul comes down from the grand sweep of cosmic narrative, through the huge history of humankind, through even the noble but puzzling story of Israel, to the events of one man in very recent history, the one man whom

117 Etwa Wright, Faithfulness, 537.

118 Wright, Faithfulness, 537.

119 Vgl. zu solchen Möglichkeiten Köppe und Kindt, Erzähltheorie, 177-179.

120 Wright, Faithfulness, 505, 516, 519, 522, 535, 536.

121 Wright, Faithfulness, 472.

122 Wright, Faithfulness, 519. Hervorhebung nicht im Original. 
Paul declares to be the key to all the locks, the answer to all the longings, the king who has finally come into his inheritance.

Dass die Analogie terminologisch konsequent durchgezogen wird („main plot,“ „sub plot,“ „play within the play“ etc.), dass aber in der Anwendung auf Paulus konzeptuell der naheliegende narratologische Gehalt der Terminologie zugunsten einer anderen Schwerpunktsetzung aufgegeben wird, ist sicherlich nicht hilfreich. Es ist natürlich vollkommen legitim, die Funktion der Aufführung des Theaterstücks im Zauberwald im Hinblick auf den Hauptplot mit derjenigen zu vergleichen, welche den Ereignissen, die Jesus betreffen, für den von Wright für Paulus angenommenen Hauptplot zukommt. Doch angesichts dessen, dass Wright die Analogie einführt, um das „Chaos“ im Hinblick auf den Zusammenhang verschiedener Erzählungen bei Paulus zu verhindern, muss aufgrund der terminologischen Verwirrung ein solches Vorgehen wohl als kontraproduktiv eingestuft werden. Als tatsächlich vergleichbare Binnenerzählungen tauchen die „stories“ im Neuen Testament lediglich auf, wenn Erzählfiguren diese zum Ausdruck bringen (z. B. Apg 17,24-31 - wobei dann auch hier die Antwort auf die Frage nach dem eigentlich Plot/Thema oft vermutlich differenzierter erfolgen müsste).

\subsection{Die drei „stories“ als aufeinander folgende Handlungsphasen?}

Wie kann also der Zusammenhang der einzelnen Handlungszusammenhänge aus dem Wright'schen Entwurf verstanden werden? Sie gehören, wie bereits gesagt, sicherlich nicht derart zueinander, dass wir es dabei mit verschiedenen Ebenen derselben Erzählung zu tun hätten (auch wenn das die Rede vom Spiel-im-Spiel wie gesagt nahelegen könnte).

Lassen sie sich also vielmehr als Erzählelemente verstehen, die aufeinander folgende Abschnitte des Plots zum Ausdruck bringen? Auch diese Option ist größtenteils zu verneinen. Denn die Geschichte über das Verhältnis des Schöpfers zu seiner Schöpfung schließt ja auch das Gericht - und damit Ereignisse in der Zukunft der Menschen - ein. ${ }^{123}$ Gleichsam endet die Menschheitsgeschichte nicht mit dem Beginn der Israel-Erzählung, sondern soll durch diese überhaupt erst zu ihrem Ziel gebracht werden.

Lediglich für die Erzählungen über Israel und Jesus könnte man das Verhältnis so sehen: Jesus, der Messias, bringt als der „treue Israelit“ die zuvor noch unvollständige Erzählung Israels zu ihrem Ziel. ${ }^{124} \mathrm{Hier}$ ließe sich dann wohl auch

123 Wright, Faithfulness, 481.

124 Wright, Faithfulness, 498. 
der Ereigniszusammenhang über die Kirche chronologisch anschließen, auch wenn Wright diesen Teil der Handlung als nicht auf der Ebene der Weltanschauung realisiert ansieht. ${ }^{125}$

\subsection{Die drei „stories“ als Handlungsstränge}

Was die „three layers“"126 zu Schöpfung, Menschheit und Israel angeht, so handelt es sich dabei also vielmehr um drei Handlungsstränge. Miteinander in Beziehung stehen sie erstens darüber, dass sie alle drei im Ereigniszusammenhang um Jesus $\mathrm{zu}$ ihrem Abschluss kommen.

Dies meint Wright jedoch gerade nicht in dem Sinn - und darin liegt letztlich das Hauptcharakteristikum seines Ansatzes - dass sich diese Plots unabhängig voneinander entwickelten und sie sich nur zufällig in der Figur des Jesus kreuzten. Vielmehr seien die Handlungsstränge, und darin liegt der zweite Aspekt ihrer Verbindung, selbst in einem starken Maß aufeinander bezogen: der Menschheits-Plot stütze den Schöpfungs-Plot und der Israel-Plot stütze wiederum den Menschheits-Plot. Es ist also nicht so, dass die drei Handlungsstränge in der Sicht Wrights in Jesus „zusammenlaufen“ - vielmehr bringt Jesus als Teil des Israel-Plots diesen so voran, dass der Israel-Plot selbst seine stützende Funktion gegenüber dem Menschheits-Plot erfüllen kann und dieser wiederum gegenüber dem Schöpfungs-Plot: ${ }^{127}$

When we understand the triple narrative which forms the basis of Paul's worldview, we can see the way in which, bewildering though it often seems to us, Jesus the Messiah functions for him in relation to all three stories simultaneously. As Israel's Messiah, he has accomplished Israel's rescue from its own plight, passing judgment on the evil that has infiltrated even his own people. As Israel-in-person, which is one of the things a Messiah is ..., he has completed Israel's own vocation, to bring rescue and restoration to the human race, passing judgment on human wickedness in order to establish true humanness instead. And as the truly human one (Psalm 8, blended with Psalm 110, as in 1 Corinthians 15) he has re-established God's rule over the cosmos, defeating the enemies that had threatened to destroy the work of the creator in order to bring about new creation.

Wright stellt dies wie folgt in Abb. 60 dar (und sieht darin „the point of all these pretty little diagrams“):

125 Wright, Faithfulness, 536-537.

126 Wright, Faithfulness, 504 und 517.

127 Wright, Faithfulness, 521. 


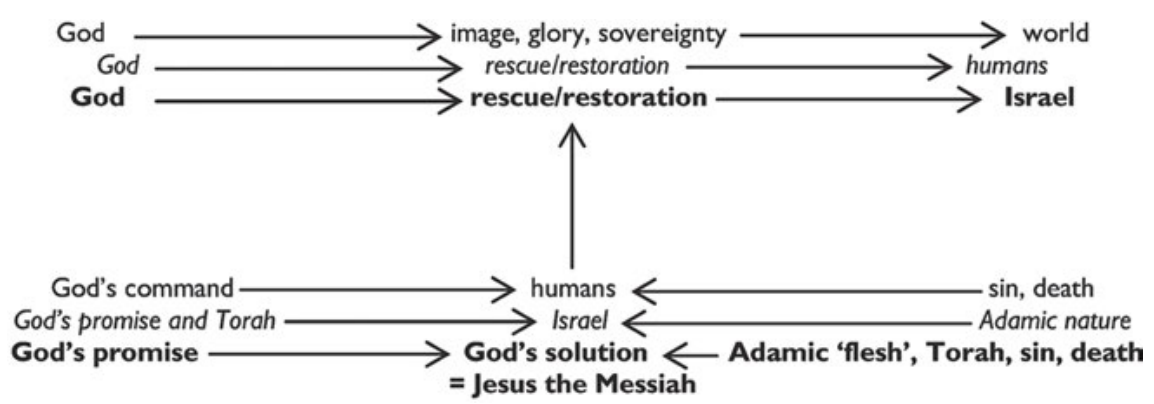

Abb. 60: Das „triple narrative,“ welches in Jesus seine „resolution“ findet.

\subsection{Die Wright'sche Erzählung der Plots}

Wenn Wrights narrativer Gesamtentwurf nur angemessen verstanden werden kann, wenn seine Skizze als Beschreibung von drei in einer Erzählung angelegten Handlungsstränge/Plots betrachtet wird, dann stellt sich natürlich die grundsätzliche Frage: Wo findet sich die korrespondierende Erzählung?

Diese Frage mutet absurd an, wenn man sich ihr von der Darstellung Wrights her nähert. Denn Wright selbst scheint die Termini „(main/sub) plots“ und „stories“ austauschbar zu verwenden. Dass dies bei der Lektüre nicht unbedingt negativ auffällt, liegt wohl daran, dass die Kategorie der ,Erzählung‘ als Bestandteil der Weltanschauung selbst so abstrakt ist, dass es nicht weiter problematisch erscheint, zwischen ihr und dem Konzept einer abstrahierten Handlung einer Erzählung hin und her zu springen. Und wenn man voraussetzt, dass die Identifizierung einer referentiellen Sequenz selbst bereits das Vorhandensein einer Erzählung ausreichend nachweist und sich diese Erzählung aus der Sequenz allein konstituiert, dann muss ja auch nicht weiter nach einem Erzählakt nachgefragt werden.

Wie oben jedoch demonstriert wurde (Abschnitt 2), kann ein solches Vorgehen nicht überzeugen: Das Erheben einer referentiellen Sequenz ist eine notwendige, aber nicht hinreichende Bedingung für die Bestimmung eines Plots (nicht hinreichend daher, da sinnhafte Zusammenhänge und Gewichtungen sich nicht allein aus der Chronologie ergeben).

Die vom Exegeten vorgenommene narrative Vertextung dieser Sequenz ist nur dann nicht das einzige erzählerische Produkt, das in der Auseinandersetzung mit dem Text begegnet, wenn davon ausgegangen werden kann, dass die referentielle Sequenz einer tatsächlichen Erzählung, also dem Produkt eines Erzählaktes, entnommen ist. 
Vor diesem Hintergrund kann nun auch klar dargestellt werden, worin das grundlegendste Problem in der Präsentation des Wright'schen Entwurfs besteht, welches eine adäquate Explikation der Konzeption Wrights im hier verfolgten narratologischen Rahmen erschwert: Wright schreibt über Paulus’ Protonarrativ(e) als wären sie Plots. Eine Erzählung ist jedoch kein Plot, noch ist der Plot im strengen Sinn Teil der Erzählung. ${ }^{128}$

Dasjenige, was tatsächlich über weite Strecken die Kennzeichen einer ,Erzählung' trägt, ist vielmehr Wrights Wiedergabe von Plots - sowohl desjenigen von Shakespeares Theaterstück als auch von Paulus' Protonarrativ(en)! In dieser Hinsicht ist Wrights Analogie in der Tat sehr erhellend, jedoch nicht in der Weise, wie er es denkt: Auch der Sommernachtstraum von Shakespeare ist schließlich keine Erzählung. ${ }^{129}$ Der von Shakespeare geschriebene Text („foul paper“ und die 1600 nach der Aufführung erschienene Quartoausgabe) enthält natürlich sprachliche Repräsentationen von Ereignissen, die allerdings ja als Bühnenanweisungen zu verstehen sind (so die ersten Worte „Enter Theseus ... “), die noch dazu viel spärlicher sind als im Falle eines modernen Filmdrehbuchs, bei welchem die Klassifizierung als Erzählung schon eher in Frage käme. ${ }^{130}$ Darüber hinaus wird in den Reden natürlich beständig auf gegenwärtiges, zukünftiges und vergangenes Handeln Bezug genommen, sodass man sagen kann, dass in den Redeabschnitten zahlreiche Erzählungen vorkommen. Viele der Ereignisse, die Wright jedoch so ausführlich beschreibt, ebenso wie deren sinnhafte Verknüpfungen, sind aber nicht dem Text Shakespeares selbst zu entnehmen. Was Wright in diesem Zusammenhang erzählt, ist die Handlung, wie er sie versteht - vermutlich aufgrund eigener Beiwohnungen von Inszenierungen des Stücks sowie anhand der Textausgabe. Wenn Wright etwa vom Spiel-im-Spiel als dem Höhepunkt des Spiels spricht, ${ }^{131}$ dann bietet er uns damit seine Interpretation der dargestellten Ereignisse.

Wenn man also in der von Wright angeführten Analogie eine Parallele zu Paulus sehen möchte, dann liegt sie genau in diesem Punkt: Als „Erzähler“ stehen sich nicht etwa Paulus und Shakespeare gegenüber, sondern Wright und Paulus: Der Stoff, aus welchem sie jeweils ihre Narrative bilden, entstammt einerseits ihrer erlebten Wirklichkeit (im einen Fall dem recht konkreten Theater-Besuch). ${ }^{132}$ Teil

128 Köppe und Kindt, Erzähltheorie, 107.

129 Siehe nun zum Thema die hier nicht mehr berücksichtigte Arbeit von Weber, Episierung im Drama.

130 Vgl. Köppe und Kindt, Erzähltheorie, 46.

131 Wright, Faithfulness, 473 Vgl. S. 472 zur Schlüsselfunktion.

132 Vgl. Wright, Faithfulness, 471 zum Verhältnis von Spiel, Spiel-im-Spiel und „audience and their ordinary lives.“ 
dieser Lebenserfahrung ist andererseits auch die Lektüre schriftlicher Quellen im einen Fall die Textausgabe des Stücks von Shakespeare und im anderen Fall die Schriften Israels und die mündlichen und schriftlichen Alltagserzählungen über das Erlebte.

\subsection{Die paulinische Leiterzählung}

\subsubsection{Ein Leiterzählakt zu Beginn der paulinischen Mission?}

Möchte man im Hinblick auf Shakespeares Stück also von einer ,Erzählung‘ sprechen, so lässt sich diese am ehesten im Text des Buches von Wright identifizieren, welchen er aufgrund der im Stück zur Darstellung gebrachten Ereignisse geschrieben hat. Was ist analog zu Paulus' Narrativ zu sagen?

Vor dem Hintergrund des letzten Abschnittes sollte klar sein, dass es sich in der Vorstellung von Wright bei diesem eigentlich gar nicht um drei „stories“ handelt - sondern lediglich um drei Plots derselben Erzählung.

Damit Wrights Konzeption Bestand haben kann, muss daher vorausgesetzt werden, dass Paulus zu irgendeinem Zeitpunkt in einem kreativen mentalen Akt all diejenigen Ereignisse, die in Wrights drei Plots eingeordnet sind, miteinander in Verbindung gebracht hat.

Dabei darf sicherlich zugestanden werden, diesen „Akt“ als einen über einen längeren Zeitraum verlaufenden Prozess zu begreifen, in welchem Paulus über den Zusammenhang verschiedener Ereigniskomplexe reflektierte und mal an der einen Stelle, mal an einer anderen, Verknüpfungen vornahm.

Die von Wright in einer anderen Publikation ${ }^{133}$ vorgelegte Rekonstruktion der „dunklen Jahre“ des Apostels zwischen seiner Bekehrung und seiner Rückkehr nach Damaskus scheinen in dieser Hinsicht tatsächlich einen geeigneten Hintergrund für eine solche kontemplative - „erzählerische“ - Phase im Leben des Paulus zu liefern: In diesem Verständnis ging Paulus nicht nach „Arabien“ (Gal $1,17 b \alpha)$, um dort zu evangelisieren. Vielmehr folgte er laut Wright seinem Selbst-

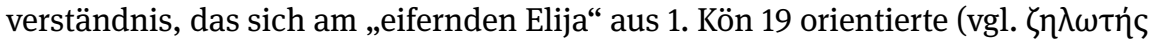
in Gal 1,14), und ging deswegen nach Arabien, um eine Vorstellung seiner neuen „job descripton“ zu entwickeln (vgl. 1. Kön 19,8 zum Berg Horeb mit Gal 4,25: тò

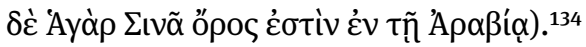

Wie auch immer man den Prozess, in welchem die paulinische Botschaft ihre Form gewann, lokalisieren und datieren möchte, ist Wright auf jeden Fall

133 Wright, Pauline Perspectives, Kapitel 10 („Paul, Arabia and Elijah [Galatians 1.17] [1996]“). 134 Wright, Pauline Perspectives, 156. 
darin zuzustimmen, dass eine solche Reflexion nicht im luftleeren Raum stattgefunden, sondern auch die „väterlichen Überlieferungen“ (Gal 1,14) mit betroffen haben dürfte - und damit die Frage nach dem Zusammenhang der geglaubten Geschichte Gottes mit seinem Volk und der Verheißungen der Schriften auf der einen Seite mit seinem apostolischen Auftrag auf der anderen.

In diesem simulierten Erzählen wäre also die Erzählung begründet, deren Plot Wright zu erheben versucht. Als grundsätzliche Voraussetzung des Wright'schen Ansatzes muss daher gelten, dass die von Wright in mehrere Handlungsstränge integrierten Ereignisse in ihrer fragmentarischen Bezeugung im paulinischen Text Ausdruck dieser einen simulierten Erzählung des Apostels sind.

\subsubsection{Der Leiterzählakt als ein die paulinische Mission begleitender Prozess?}

Die komplexe Diskussion über die Ursprünge der paulinischen Theologie und deren etwaige Entwicklung wird auch durch eine Fokussierung auf einen solchen narrativen „Leiterzählakt“ natürlich nicht obsolet. Auch wenn man die theologische Reflexion des Paulus vor allem als Integration verschiedener narrative Aspekte versteht, ist nicht ausgeschlossen, dass einzelne Handlungsabschnitte des umfassenden Protonarrativs angesichts bestimmter Umstände im Laufe der Zeit größere Aufmerksamkeit und Ausgestaltung (vgl. Röm 9-11) erfuhren oder auch korrigiert wurden (vgl. etwa das chronologische Argument in Gal 3,15-17, das in Röm 4,9-12 wohl nuancierter vorgetragen wird). ${ }^{135}$

Nicht zuletzt stellt auch die bei Hays anzutreffende, von Wright vereinnahmte Rede eines „umfassenderen“ Narrativs (vgl. Kapitel 15, Abschnitt 4.5.1) eine Alternative zur Konzeption Wrights dar. Bei Hays ist diese „Leiterzählung“ nämlich nicht eine monolithische Größe, mit welcher Paulus an individuelle Situationen herantritt. Sie weist vielmehr eine gewisse Flexibilität auf und wird immer wieder neu modifiziert, je nachdem, welche Erfahrungen sich ergeben und neu interpretiert werden müssen.

Das sich auf diese Weise graduell herausbildende umfassende weltanschauliche Narrativ ist bei Hays daher gerade nicht der „Kern“ der paulinischen Theologie, nach dem er in seiner Dissertation fahndete (vgl. Kapitel 15, Abschnitt 2.3.1). Dieser besteht in der Jesus-Erzählung und die Schriftlektüre stellt ebenso eine spezifische „Situation“ dar, in welcher der Kern in Interaktion mit dem Kontext tritt, wie dies im Fall eines konkreten Problems in der Gemeinde ist. Die umfassende Leiterzählung wäre daher im selben Sinn ein Produkt der Interaktion des Kerns mit sich wandelnden Umständen der paulinischen Mission.

135 Vgl. hierzu Dunn, Galatians, 182-183. 


\subsection{Von den Erzählfragmenten zur Leiterzählung - und von der Leiterzählung zu den drei Handlungssträngen}

Unabhängig vom genauen Ablauf und der zeitlichen Ausdehnung des „Leiterzählaktes“ ist aus narratologischer Sicht auf jeden Fall die Rekonstruktion der daraus hervorgehenden Protoerzählung auf der einen Seite und die Erhebung ihrer Plots voneinander zu trennen. Aus den konkreten Erzählfragmenten im Text müsste man zunächst den simulierten Text der mentalen Erzählung rekonstruieren. Von diesem Narrativ selbst zu unterscheiden ist jedoch Wrights Beschreibung des Plots.

Dass die beiden Größen nicht einfach deckungsgleich sind, zeigt schon die Tatsache, dass Wright die drei Handlungsstränge nacheinander präsentiert. Demgegenüber ist natürlich nicht automatisch gesagt, dass eine solche Einteilung und Anordnung der Ereignisse auch im paulinischen Akt des Erzählens in dieser Konfiguration vorliegen würde. Auch die Handlungsstränge, die einem literarischen Erzählwerk entnommen und dann beispielsweise in einer Rezension so wiedergegeben werden, müssen nicht unbedingt mit aneinander gereihten Handlungssequenzen korrelieren (sie tun dies in den allerseltensten Fällen).

Die Beschreibung der Handlung(en) stellt somit einen Schritt dar, der die Rekonstruktion des Protonarrativs bereits voraussetzt und interpretatorisch auch weit über diesen hinausgeht. Ob die ,Handlung im Sinne der Gesamtmenge der zum Ausdruck kommenden Geschehnisse auch mehrere ,Handlungen' im Sinne wesentlicher Zusammenhänge mehrerer Ereigniskomplexe konstituiert, ${ }^{136}$ erfordert eine ausführliche Betrachtung des rekonstruierten Protonarrativs.

Bei der Identifizierung verschiedener Handlungsstränge hängen nun aber die interpretatorischen Entscheidungen nicht zuletzt auch von den Parametern des Erzählens ab, ergeben sich also unter anderem auch daraus, wie die Übergänge innerhalb der temporalen Ordnung gestaltet sind, ob und wie zeitliche Sprünge, Ortswechsel, Wechsel der Fokalisierungsinstanzen etc. vorliegen. Auch die sinnhaften Verknüpfungen, die im Vorgang des Erzählens zwischen einzelnen Ereignissen hergestellt werden, entscheiden mit darüber, ob ein bestimmter Vorschlag über den Zusammenhang verschiedener Plots einer Erzählung plausibel ist. Da Plots Erzähltexten nicht einfach entnommen werden können, sondern Interpretationen voraussetzen, können diese natürlich auch unterschiedlich plausibel sein.

Wieder ist Wrights Analogie des Sommernachtstraums erhellend: Wenn er behauptet, die sich im Stück ereignenden Geschehnisse ließen sich mehreren

$136 \mathrm{Zu}$ den beiden Bedeutungen von „Handlung“ siehe oben, Kapitel 3, Abschnitt 5.3. 
Handlungssträngen zuordnen, die im „play within the play“ ihren Höhepunkt fänden, dann geht er offenbar davon aus, dass damit die dem Stück zugrundeliegende Protoerzählung des Dichters korrekt erfasst wird. Ob er die in der Aufführung nur fragmentarisch zum Ausdruck kommende mentale Erzählung Shakespeares damit aber richtig interpretiert hat, ist durchaus fraglich. Immerhin ließe sich dieses Ereignis der Aufführung streichen, ohne die anderen Handlungsstränge signifikant zu beeinflussen, lediglich der stützende Handlungsstrang der Theaterleute bliebe unvollständig ${ }^{137}$ und die Erzählung würde etwas „Witz“ (vgl. Kapitel 3, Abschnitt 3.4.4.4) vermissen lassen.

Ebenso kann natürlich auch für Wrights Rekonstruktion des Plots der paulinischen Protoerzählung gefragt werden, ob die Ereignisse tatsächlich im „Text“ (wie er simuliert erzählt wurde und fragmentarisch zum Ausdruck kam) so miteinander in Beziehung gesetzt werden, so erzählt werden, dass die Inbeziehungsetzungen der einzelnen Handlungsstränge begründet sind.

Worauf, so könnte man etwa fragen, basiert die Überzeugung, dass die Erzählung über die Menschheit der Erzählung über die Schöpfung untergeordnet ist? Die Rede davon, dass die Ereignisse, welche die Schöpfung betreffen, ein „larger framework" ${ }^{138}$ darstellten, muss sehr präzise bestimmt werden: Die Tatsache, dass sie in der chronologischen Aufstellung, wie sie mit der Handlungsbestimmung einhergeht, die „rahmenden“ Ereignisse liefern, bedeutet nicht, dass sie den gewichtigsten Handlungsstrang konstituierten. ${ }^{139}$ Die Ereignisse im Umkreis der Hochzeit von Theseus und Hippolyta liefern zwar den Kontext, in welchem sich die anderen

137 Zur „Streichbarkeit“ von Ereignissen als mögliches Kriterium vgl. Köppe und Kindt, Erzähltheorie, 105-106.

138 Vgl. Wright, Faithfulness, 494: „This narrative, told in a hundred different hints and fuller passages in Paul's writings, is the element that most western readers over the last half millennium or so assume is the main story: humans sin, God rescues them, humans are saved. I hope it is becoming clear that though this is indeed one way (a somewhat truncated way) of pointing to the subplot in question it is by itself inadequate, and that when we explore this subplot we see the $\sin /$ salvation dynamic within its larger framework.“

139 Es soll hier nicht behauptet werden, dass Wright die Rolle des Handlungsstrangs der Schöpfung allein aufgrund dieser „rahmenden“ Position der in ihr enthaltenen Ereignisse annimmt. Es fällt jedoch schon auf, dass er im eröffnenden Abschnitt einerseits vom „larger framework“ spricht und andererseits eine Gewichtung vornimmt: „This ,cosmic' story ... is not often found explicitly within Paul's writings, but when it does show up we should realize that it is crucial and foundational for everything else. We would be correct to suppose that it is in principle present to his heart and imagination, as a shaping influence on all else, even when it remains unstated“ (Wright, Faithfulness, 475). Vgl. aber auch Wright, Faithfulness, 484, wo er explizit die Möglichkeit anspricht, dass der „framing plot of creator and creation“ prinzipiell auch auf eine losere Weise mit den Subplots verbunden sein könnte, auch wenn er denkt, dass dies bei Paulus eindeutig nicht der Fall sei. 
Handlungsstränge entfalten, das dominierende Thema der Liebe ${ }^{140}$ wird aber ja wohl in den die vier jungen Athener betreffenden Handlungssträngen entfaltet. ${ }^{141}$

Könnte man die von Wright in die drei Plots integrierten Ereignisse also auch auf eine solche Weise erzählerisch präsentieren, sodass sich die drei Plots nicht plausibel entnehmen ließen? Die Antwort lautet: selbstverständlich! Es ist immerhin davon auszugehen, dass die „Gegner“ des Paulus nicht einfach mit einem anderen Set an Ereignissen arbeiteten, sondern diese vor allem auf eine andere Art und Weise verknüpft sahen. ${ }^{142}$

Für die Rekonstruktion der Protoerzählung, die Wright annimmt, ist dies von großer Bedeutung: Seine Rekonstruktion der Handlung als drei verbundene Handlungsstränge setzt voraus, dass es auch eine Erzählung mit sehr spezifischer Konfiguration gibt, aus welcher die einzelnen Plots erhoben werden können.

Eine exegetische Bewertung des umfassenden Entwurfs von N. T. Wright würde daher insbesondere einen Fokus auf die „Verbindungsstücke“ zwischen denjenigen Ereignissen, die von Wright verschiedenen Handlungssträngen zugeordnet werden, erfordern. Es genügt nicht, dass Paulus sowohl über die Schöpfung schreibt als auch über die Menschheit als auch über Israel. Die entscheidende Frage ist vielmehr: Lassen sich im Text sprachliche Rudimente des postulierten „Leiterzählaktes“ ausmachen, von welchem angenommen wird, dass er das weltanschauliche Narrativ des Paulus begründete?

Im Zentrum stehen also Aussagen, welche die Erzählungen über die Menschheit als Teil (und zwar mit der von Wright postulierten Funktion!) eines die Schöpfung als Ganzes betreffenden Geschehenzusammenhangs schildern,

140 Zum „Thema“ vgl. Kapitel 3, Abschnitt 5.3.

141 Vgl. Wright, Faithfulness, 475, der den Theseus/Hippolyta-Strang explizit mit dem Schöpfungs-Strang parallelisiert. Ein späterer Kommentar (Wright, Faithfulness, 485) scheint darüber hinaus zu implizieren, dass die „rahmenden“ Ereignisse tatsächlich auch den inhaltlichen Schwerpunkt darstellten: „As with Shakespeare, so with Paul: it is when we get to the first subplot that we feel the story is really starting. Indeed, just as some theatregoers may leave the play thinking only of Lysander and Hermia, Demetrius and Helena, and perhaps the strange story of Bottom the Ass by which their problems are first intensified and then resolved, so some readers of Paul come away with the impression that his sole concern is the human plight and the strange means of its resolution. It is important, however, to see that, for Paul, the human plight is related directly to the overarching plot.“

142 In genau diesem Aspekt der unterschiedlichen Ausgestaltung des Erzählens liegt auch (a) der Schlüssel zum Verständnis des Umstands, in welchem sich Hays und Wright von der Heilsgeschichte absetzen und (b) der Grund für das Missverständnis, sie könnten dieser Bewegung ohne Probleme zugerechnet werden: Die von den beiden Autoren angenommenen Plots basieren auf postulierten paulinischen Erzählungen, in denen sich die Geschehnisse um - beispielsweise - Abraham und die Gemeinde nicht einfach als zwei zeitlich aufeinanderfolgende parallele Heilstaten verstehen lassen. 
solche Schilderungen über Israel, in denen deutlich wird, dass diese als stützenden Erzählzüge für den die Menschheit betreffenden Handlungsstrang fungieren, solche, in denen schließlich die Ereignisse um Jesus in wegweisender Funktion in die Geschichte des Volkes Gottes integriert werden.

\subsection{Von der paulinischen Leiterzählung zu paulinischen Einzelerzählungen}

\subsubsection{Fehlende Ereignisse}

Im letzten Abschnitt 5.7 wurde umrissen, wie der von Wright postulierte Plot, bzw. die diesen konstituierenden drei Handlungsstränge, anhand von Fragmenten der tatsächlichen Protoerzählung plausibilisiert werden muss, und dass in dieser Hinsicht gerade diejenigen Elemente der Texte in den Paulusbriefen relevant sind, welche die sinnhafte Verknüpfung von Ereignissen betreffen, die von Wright unterschiedlichen Handlungssträngen zugeordnet werden. Das betrifft, stark vereinfacht, insbesondere die folgenden Verbindungen:

Erschaffung der Welt $>$ Erschaffung des Menschen $>$ Das Problem der Sünde $>$ Abrahamsverheißung $>$ Geschichte Israels $>$ Jesu Wirken und Schicksal $>$ Restauration Israels/Errettung der Menschheit/ „Verherrlichung“ der Welt. ${ }^{143}$

Was ist nun mit Fragmenten, in welchen Ereignisse in dieser Folge übersprungen $\mathrm{zu}$ werden scheinen?

Wright verweist etwa auf Gal 1,4 als ein Beispiel dafür, dass der die Menschheit betreffende Plot innerhalb des zentralen „overarching narrative,“ welches die Schöpfung betrifft, $\mathrm{zu}$ verstehen sei. ${ }^{144}$ Doch kann dieser Text tatsächlich verstanden werden als ein Fragment derjenigen Erzählung, deren Plot die oben gelistete Ereignissequenz beinhaltet (und darin auf sehr spezifische Weise Verbindungen herstellt)? Es liegt die Vermutung nahe, dass man aus Gal 1,4 eher auf ein Protonarrativ schließen würde, aus welchem sich der folgende Plot erheben ließe:

(Erschaffung der Welt $>$ Erschaffung des Menschen) $>$ Das Problem der Sünde [ $>$ Abrahamsverheißung $>$ Geschichte Israels] $>$ Jesu Wirken und Schicksal $>$ Errettung der Menschheit/ (,Verherrlichung“ der Welt).

143 In Wrights Darstellung der Aktanten (Wright, Faithfulness, 521) fallen „image, glory, sovereignty,“ „rescue/restoration,“ und „rescue/restoration“ zusammen. Auch dieses Ergebnis ist aber noch weiter temporal aufzudröseln. Wir gehen hier nicht weiter darauf ein, inwiefern diese Komplexitätsreduzierung gerade nicht für den Nutzen des Darstellungsmittels spricht, den Wright an dieser Stelle stark macht.

144 Wright, Faithfulness, 477. 
Die an den Rändern eingeklammerten Elemente ließen sich eventuell als impliziert postulieren, ${ }^{145}$ doch was ist mit der Verbindung des Wirkens Jesu mit dem die Menschheit betreffenden Handlungsstrang? Die in eckige Klammern gesetzten Elemente scheinen im Text keine Rolle $\mathrm{zu}$ spielen. Wie ist das $\mathrm{zu}$ verstehen - vorausgesetzt, es liegt tatsächlich ein Zusammenhang mit der von Wright postulierten umfangreichen Leiterzählung vor? Es stehen drei Optionen zur Auswahl, die im Folgenden kurz erläutert werden sollen. ${ }^{146}$

\subsubsection{Fragmentarischer Ausdruck der in der Erinnerung präsenten Leiterzählung}

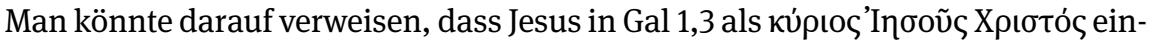
geführt wird. Wenn man, wie Wright, Xpıбтóৎ als „Messias“ versteht ${ }^{147}$ und man weiterhin den Aspekt der Repräsentation des Volkes als zentrales Merkmal des paulinischen Messianismus betrachtet, ${ }^{148}$ dann könnte man argumentieren, dass in dieser Bezeichnung der im treuen Israeliten gipfelnde Erzählstrang über Israel vorausgesetzt sei. Paulus hätte dann also sehr wohl seine ursprüngliche umfassende Protoerzählung vor Augen gehabt, als er diesen Text schrieb. Gal 1,4 wäre also in der Tat ein Fragment des großen, von Wright postulierten Protonarrativs.

Dass dieses Protonarrativ die Erzählzusammenhänge über Israel und ihren Messias überhaupt beinhaltet, müsste natürlich unabhängig davon erst demonstriert werden. Dasselbe gilt für die Überzeugung, dass Xpıбтós das Israel-Element aufruft. Entscheidend ist an dieser Stelle jedoch, dass man diese Passage unter den erläuterten Bedingungen als Ausdruck des in der Erinnerung präsenten ursprünglichen Protonarrativs verstehen könnte (siehe oben, Abschnitt 5.6).

\subsubsection{Kompakte Neuerzählung}

Dies ist jedoch nicht die einzige zur Verfügung stehende Möglichkeit, das „Fehlen“ von Elementen der umfassenden Leiterzählung zu erklären. Selbst wenn man von der Existenz einem ursprünglichen umfassenden Erzählaktes ausgeht, können

145 Wright, Faithfulness, 477 weist darauf hin, dass nicht an eine Rettung „out of the cosmos“ gedacht sei. Durch den Willen des Vaters, den Schöpfergott, könnte man den „kosmischen“ Handlungsstrang als impliziert gegeben sehen.

146 Vgl. grundsätzlich auch Schumann, Gülich, Lucius-Hoene und Pfänder, Hg., Wiedererzählen zu den folgenden kurz angerissenen Vorschlägen.

147 Vgl. für eine neuere Arbeit, die Wrights These stützt, Novenson, Christ. Siehe auch die aktuelle Darstellung der Diskussion bei Lee, „Messianism.“

148 Siehe hierzu nun die Bewertung bei Hewitt und Novenson, „Participationism.“ 
dem in der Folge schließlich zahlreiche weitere erzählerische Einzelakte folgen, welche unabhängig auf dieselben Ereignisse Bezug nehmen.

Dass der Ereigniszusammenhang über Israel und den Messias „vorausgesetzt" ist, kann dabei ebenfalls Verschiedenes heißen. Es ist möglich, dass eine ausführliche Erzählung bestimmte Ereignisse als notwendige Voraussetzung für späteres Geschehen identifiziert, eine prägnantere Schilderung allerdings auf der Ebene des Erzählens trotzdem ohne dieses Bindeglied auskommen kann.

Die in Abb. 61 folgenden beiden fiktionalen Alltagserzählungen eines fiktiven Mannes mit dem Namen Peter demonstrieren diese Konstellation:

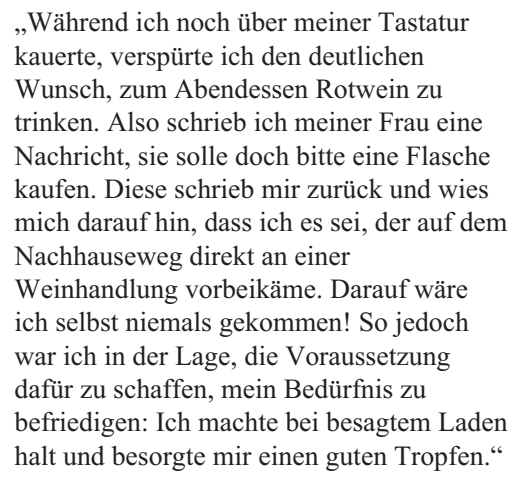

Abb. 61: Beispiel für eine kompakte Neuerzählung.

Der Hinweis von Peters Frau ist auch in der zweiten Erzählung „vorausgesetzt“ in dem Sinn, dass Peter die darin geschilderten beiden Ereignisse nie wahrheitsgemäß hätte erzählen können, wenn seine Frau ihm nicht den entscheidenden Ratschlag gegeben hätte - das Ereignis der hilfreichen Textnachricht ist somit eine Bedingung auf der Ebene des Erzählaktes selbst.

Es ist nun aber problemlos denkbar, dass Peter die beiden Versionen jeweils einem anderen Freund erzählt und dabei im zweiten Fall überhaupt nicht an seine Frau denkt. Es wäre dann dem Verständnis seiner Kommunikationsabsicht geradezu abträglich, wenn man die zweite Erzählung durch den Plot der ersten auffüllte. ${ }^{149} \mathrm{Um}$ die narrative Verknüpfung der in den beiden Aussagen der zweiten Erzählungen enthaltenen Ereignisse angemessen zu ver-

149 Vielleicht ist Peters Frau im ersten Fall zugegen und ihre Präsenz erinnert Peter daran, ihrer Rolle in dem Geschehen angemessen Respekt zu zollen, während er im zweiten Fall nur das erzählt, was ihm selbst wirklich wichtig ist. 
stehen, gilt es also gerade, diese als Produkt eines eigenständigen Erzählaktes wahrzunehmen.

Auf Paulus übertragen heißt dies, dass man beim Verweis auf ein umfassendes im Hintergrund stehendes Protonarrativ Vorsicht walten lassen muss. Selbst wenn für die Genese mancher kompakten Erzählungen ein ursprünglicher Leiterzählakt von Bedeutung gewesen sein mag, bedeutet dies nicht, dass es zum Verständnis der individuellen knappen Erzählung beiträgt, diesen größeren narrativen Zusammenhang aufzurufen. Man kann dabei sogar die eigentliche, auf die spezifische Situation zugeschnittene Kommunikationsintention gerade verkennen.

\subsubsection{Raffende Variation der Leiterzählung}

Es ist aber auch eine Variante denkbar, welche eine größere Kontinuität zwischen dem ursprünglichen Erzählakt und Folgeakten voraussetzt. Es wurde bereits erwähnt, dass es im Fall der doppelten Erzählung von Peter möglich ist, dass dieser bei der zweiten Version die ihm in der Erinnerung präsenten Ereignisse direkt miteinander verknüpfte, ohne das Ereignis der Kommunikation mit seiner Frau dabei vor Augen zu haben.

Ebenso denkbar wäre aber natürlich auch der Fall, dass Peter zuerst die erste Version formuliert und diese dann die Grundlage für spätere Rezitationen bildet. Bei einem Treffen der Anonymen Alkoholiker könnte er sich dennoch - ganz bewusst - entscheiden, seine Frau aus dem Spiel zu lassen, weil er sie schützen möchte und erkennt, dass die Haupthandlung seiner Erzählung auch ohne ihre Nennung bestehen bleibt.

Auf die Paulusbriefe übertragen bedeutet dies: Ebenso wie wir auf der Grundlage einer paulinischen Erzählung einen Plot erheben können, stand dieser Abstraktionsschritt natürlich auch Paulus selbst zur Verfügung. Und in der Auseinandersetzung mit spezifischen Texten weist Paulus durchaus eine starke Tendenz zu einer solchen interpretativen Auswertung auf. ${ }^{150}$

Man muss daher nicht annehmen, dass alternative, knapp formulierte Erzählungen die „Leiterzählung“ bei Paulus vollständig verdrängen. Es kann auch sein, dass er sich anhaltend darüber bewusst war, dass in seiner Vorstellung die Funktion Jesu im Hinblick auf die Menschheit in auf Israel bezogenen Ereignissen begründet war, dass er sich jedoch in spezifischen Situationen entschied, diesen Handlungsstrang seiner Leiterzählung selbst zum Gegenstand einer neuen Erzählung zu machen.

150 Für ein besonders deutliches Beispiel siehe Kapitel 14, Abschnitt 3.5.1 zu Röm 11,17-23. 
Auch in diesem Fall ist dann freilich der neue Erzählakt als solcher wahrzunehmen, ebenso wie beispielsweise der vom Autor für sein Buch verfasste Klappentext, welcher sich auf die Haupthandlung konzentriert, eine erzählerische Hervorbringung eigener Güte darstellt. ${ }^{151}$

Wenn wir bei Paulus also auf Erzählungen stoßen oder diese aus EreignisRepräsentationen als Protoerzählungen rekonstruieren, in denen Aspekte ausgelassen werden, die wir für einen Teil seiner grundlegenden Leiterzählung halten, so dürfen wir nicht - wie Wright es zu tun scheint - voraussetzen, dass diese ausgelassenen Elemente hinzuzudenken sind und der untersuchte Text sich somit als Fragment der Leiterzählung behandeln lässt.

Umgekehrt gilt allerdings auch: Für den Fall, dass sich eine raffend erzählte Erzählung von der Leiterzählung abgrenzen lässt, bedeutet dies nicht zwangsläufig, dass die kürzere Version schlicht „gleichwertig“ zu behandeln ist oder gar die vorausgehende Version korrigiert. Sie ist zwar als Produkt eines eigenständigen Erzählaktes zu würdigen, unter der Voraussetzung bestimmter Zielsetzungen kann allerdings mit gutem Grund an der Zentralität der ausführlicheren Erzählung festgehalten werden:

(1) Wer sich etwa aus der Perspektive eines Historikers mit den Voraussetzungen von Peters Alkoholkonsums beschäftigt, für den ist wichtig, dass sich hinter der konsekutiven Verbindung der beiden Ereignisse der zweiten Erzählung ein komplexeres Geschehen verbirgt. Wer also wissen möchte, warum ${ }^{152}$ Paulus in Gal 1,4 schreiben kann, dass Jesus sich hingab, „um uns aus diesem bösen gegenwärtigen Zeitalter herauszureißen, “ der mag zurecht nach einem volleren Narrativ fragen - egal ob er dies nun an anderer Stelle vollständig expliziert findet, oder aus anderen Fragmenten rekonstruiert. Wichtig ist dann nur, zu beachten, dass es diese Fragmente sind, welche eine Erzählung erkennen lassen - und dass diese Erzählung von der in Gal 1,4 gebotenen zu unterscheiden ist.

(2) Wer Zeuge beider Erzählungen Peters wurde, könnte ihm die herausfordernde Frage stellen, ob er nicht auch im zweiten Fall „eigentlich“ über seine Frau erzählt habe. Über den moralisierenden Unterton hinweggehend, könnte Peter zugestehen, dass er zwar nicht an sie gedacht hätte, sein Kauf aber letztlich natürlich nur aufgrund ihres Eingreifens ermöglicht wurde. Zwei Erzählakte in ihrer Eigenständigkeit wahrzunehmen, bedeutet also nicht, dass sie gleichwertig behandelt werden müssten. Wer an der Systematisierung

151 Vgl. Kapitel 9, Abschnitt 4 zum „Klappentext.“

152 Siehe etwa Kapitel 2, Abschnitt 4.3.2 zu einer von einem externen Standpunkt aus erfolgenden Analyse von Erzähltem. 
des Denkens des Paulus interessiert ist, mag die Betonung der umfassenderen Erzählungen gegenüber kürzeren Versionen insofern gerechtfertigt halten, als er oder sie letztere als verkürzend bewerten wird. Auch wenn Paulus Geschehnisse unter Auslassung bestimmter Elemente erzählen kann, könnte er - vor die Wahl gestellt - durchaus zustimmen, dass die prägnantere Schilderung nur vor dem Hintergrund der umfassenderen richtig zu verstehen sei. Gerade hier, in einem imaginierten Dialog mit Paulus über dessen zahllose Erzählungen und Erzählfragmente, über den angemessenen narrativen Verstehensrahmen, mag der Ansatz von Wright sein eigentliches Potenzial entfalten. Mit solchen Erwägungen verlassen wir jedoch den Bereich der nach der Aussageabsicht fragenden Exegese und arbeiten an einem Beitrag zu einer biblischen Theologie. ${ }^{153}$ 
